\title{
Primeras evidencias de un banquete: análisis arquitectónico y material de la estancia S-1 del yacimiento de Casas del Turuñuelo (Guareña, Badajoz) ${ }^{1}$
}

\section{First evidence of a banquet: architectural and material analysis of room S-1 of the site Casas del Turuñuelo (Guareña, Badajoz)}

\author{
Esther Rodríguez González y Sebastián Celestino Pérez²
}

Recibido: 15-06-2019

Aceptado: 28-09-2019

\section{Resumen}

En el año 2016, durante la II Campaña de excavaciones en el yacimiento de Casas del Turuñuelo, se procedió a la excavación del vestíbulo y la estancia S-1, comúnmente conocida como estancia del banquete. En este trabajo se analizan los hallazgos materiales y las estructuras arquitectónicas de este espacio, a través de cuyo estudio hemos podido determinar la funcionalidad de la estancia, diferenciando la existencia de dos actividades distintas pero continuas en el tiempo: la preparación y cocinado de los alimentos y su posterior consumo. Esto nos ha permitido reconstruir la secuencia completa y los elementos empleados en cada una de las fases del banquete celebradas en esta habitación.

\section{Palabras clave:}

Tarteso, Valle Medio del Guadiana, ‘Casas del Turuñuelo', arquitectura en tierra, banquete.

\begin{abstract}
In the year 2016, during the second excavation campaign at the archaeological site of Casas del Turuñuelo, the vestibule and the S-1 room were excavated, considered as the banquet room. In this work we analyse the material and the architectural findings produced in this space. Building on this study, we were able to identify the functionality of the room. In this regard, we have differentiated the existence of two different continuous activities over time: the preparation and cooking of food and its subsequent consumption. This has allowed us to reconstruct the complete sequence and the elements used at all stages of the banquet carried out in this room.
\end{abstract}

\section{Key words:}

Tartessos, central Guadiana Valley, 'Casas del Turuñuelo', earthen architecture, banquet.

\footnotetext{
1 Este trabajo se integra dentro del Proyecto de Investigación I+D+i: "Construyendo Tarteso: análisis constructivo, espacial y territorial de un modelo arquitectónico en el valle medio del Guadiana” (HAR 2015-63788-P).

2 Instituto de Arqueología de Mérida, CSIC, Plaza de España, 15. 06800, Mérida (Badajoz), esther.rodriguez@iam.csic.es, orcid.org/0000-0002-5813-9035; scelestino@iam.csic.es; orcid.org/0000-0002-2050-7090.
} 


\section{INTRODUCCIÓN}

Uno de los aspectos por los que destaca el yacimiento de Casas del Turuñuelo (Guareña, Badajoz) es por su estado de conservación. Hasta la fecha, el yacimiento extremeño es considerado un ejemplo único de la arqueología peninsular, entre otras razones, porque conserva en pie sus dos plantas constructivas, separadas entre sí por una escalinata monumental, con alzados que en algunas estancias alcanzan los $5 \mathrm{~m}$ de altura. A los restos arquitectónicos se suman los elementos materiales: piezas cerámicas, metales, una escultura de mármol o piezas de vidrio procedentes de diversos puntos del Mediterráneo, semillas, tejidos o maderas, que nos marcan la importancia de este enclave fechado, en el momento de su amortización, a finales del siglo $\mathrm{V}$ a.C., dentro de lo que consideramos la fase final de Tarteso.

En este sentido, y aunque convencionalmente Tarteso se circunscribe al valle del Guadalquivir, Huelva y Cádiz, y a un espacio temporal entre los siglos VIII y VI a.C., no cabe duda de que su influencia cultural llegó pronto al Valle Medio del Guadiana, donde yacimientos como Cerro Borreguero, la necrópolis de Medellín o el primer santuario de Cancho Roano, entre otros, son prueba evidente de ello. Todos estos yacimientos continuaron su actividad hasta finales del siglo $\mathrm{V}$ a.C. sin ninguna interrupción y manteniendo la esencia heredada de la cultura tartésica. Por ello, consideramos que en el valle Medio del Guadiana hay una estabilidad cultural que sin embargo no se aprecia de forma tan clara en el Guadalquivir; en consecuencia, la cultura tartésica siguió presente en esa zona del interior, con algunos elementos originales heredados de su influencia atlántica, hasta su total desaparición, a finales del siglo $\mathrm{V}$ a.C. Este final coincide con la amortización de los monumentales edificios ocultos bajo túmulo que caracterizan la ocupación del territorio el valle medio del Guadiana, uno de cuyos mejores exponentes es el de Casas del Turuñuelo. A este periodo lo venimos denominando como Tartésico Final (Celestino, 2016; Celestino y López-Ruiz, 2016). Asimismo, huimos de la clásica y confusa clasificación de "orientalizante" para referirnos a este periodo histórico - bien utilizada sin embargo para tratar problemas estilísticos - y más aún del denominado "post-orientalizante", totalmente inconsistente a tenor de la continuidad cultural en el valle del Guadiana a la que hemos aludido (Rodríguez González, 2018, con bibliografía).

De ese modo, el análisis y estudio de la arquitectura y los elementos materiales documentados durante las excavaciones de Casas del Turuñuelo nos está permitiendo reconstruir diversos aspectos de la vida cotidiana del enclave y, por lo tanto, de las sociedades tartésicas del suroeste peninsular durante la I Edad del Hierro. Sin embargo, debemos ser conscientes de que la imagen o lectura que actualmente obtenemos del estudio del yacimiento de Casas del Turuñuelo procede de la escena final que sus habitantes han querido perpetuar y transmitirnos con el acto de amortización del edificio y sus materiales; una imagen que posiblemente tenga poco o nada que ver con las actividades llevadas a cabo en el enclave a lo largo de sus años de vida. Resulta de vital importancia aclarar este aspecto antes de abordar el presente estudio, con el objetivo de alertar al lector de la carga simbólica que se desprende del espacio objeto de estudio; una carga simbólica que en repetidas ocasiones se ha empleado para definir la funcionalidad de este enclave que, por otro lado, nos sigue resultando desconocida a falta todavía de excavar más de la mitad de la extensión que ocupa el túmulo.

Aeste respecto, el presente trabajo está destinado al análisis de los restos documentados durante las excavaciones de la estancia $\mathrm{S}-1$, cuyos materiales arqueológicos y elementos arquitectónicos nos narran las fases de preparación y celebración de un simposio que debió celebrarse justo antes de la clausura del edificio y cuyas primeras evidencias ya fueron documentadas durante las excavaciones de la estancia 100, un espacio publicado en esta misma revista (Rodríguez González y Celestino, 2017). Ambos espacios constituyen dos piezas de un enorme puzle cuya reconstrucción sacará a la luz la complejidad del ritual que puso fin a la vida del edificio de Casas del Turuñuelo, de ahí la importancia de ir dando a conocer los resultados arqueológicos obtenidos de la excavación y estudio de cada una de las habitaciones que conforman esta magnífica construcción. A este respecto, cabe añadir que la última pieza sumada a este enorme rompecabezas es la hecatombe de animales documentada en el patio del piso inferior del edificio (Celestino y Rodríguez González, 2019a).

El yacimiento de Casas del Turuñuelo parte con la ventaja de ser un contexto cerrado, un elemento esencial de cara a abordar el análisis de la huella arqueológica que una actividad ritual deja en un enclave determinado. El edificio fue clausurado en un momento concreto de finales del s. $\mathrm{V}$ o en los primeros años del IV a.C. en conexión con la amortización de otro conjunto de yacimientos del mismo horizonte cultural en el valle medio del Guadiana (Rodríguez González, 2018). De ese modo, y aunque la construcción fue objeto de un incendio 

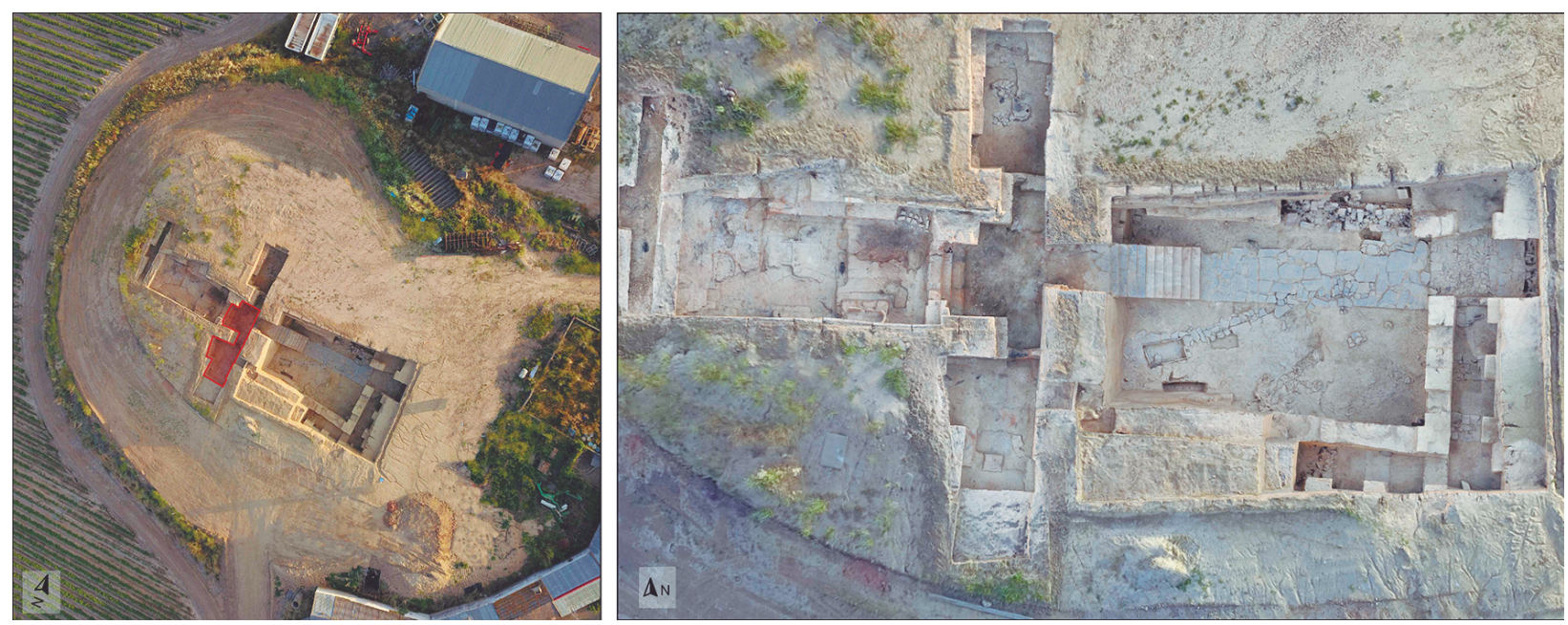

Figura 1. Vista aérea del túmulo de Casas del Turuñuelo (junio 2018) y fotogrametría del área excavada. El contorno rojo marca la ubicación del vestíbulo y la estancia $S$-1 o del banquete. (Montaje: Carlota Lapuente. (C) Construyendo Tarteso).

generalizado y una minuciosa destrucción posterior, los materiales fueron depositados en las diferentes estancias con una intencionalidad que nos está permitiendo reconstruir las actividades desarrolladas en cada una de las habitaciones del edificio.

Así, el análisis arquitectónico y material de los restos hallados en la estancia S-1, comúnmente denominada como estancia del banquete, nos han permitido acercarnos a la existencia de un espacio en el que claramente puede distinguirse la realización de dos actividades distintas pero continuas en el tiempo: por un lado, la preparación y el cocinado de los alimentos y, por otro lado, el consumo de los mismos. La diferencia entre ambos escenarios radica, principalmente, en los objetos materiales empleados, principalmente la cerámica, cuyo estudio nos permite presentar una primera lectura de los restos documentados. Llegados a este punto, posiblemente la tarea más compleja del trabajo, a la que sin duda dedicaremos una breve reflexión tras la presentación del material recuperado, sea determinar aquellos aspectos que diferencian actividades cotidianas, como el acto de comer diariamente, de aquellas celebraciones excepcionales, grupo en el que se incluyen los banquetes rituales, principalmente vinculados a actos religiosos o funerarios (Sardá, 2010).

Para un futuro próximo quedará entonces la tarea de eliminar esa carga ritual que actualmente se desprende de los hallazgos realizados en las diferentes estancias del edificio de Casas del Turuñuelo y descifrar cuál era el papel que este monumental edificio desempeñó en el poblamiento del valle medio del Guadiana.

\section{CoNTEXTO ARQUEOLÓGICO Y ESPACIAL DE LA ESTANCIA DEL BANQUETE DENTRO DEL EDIFICIO DE CASAS DEL TURUÑUelo}

Durante el año 2016 tuvo lugar la II Campaña de excavaciones arqueológicas en el yacimiento tartésico de Casas del Turuñuelo. La documentación durante la anterior campaña de un único punto de acceso a la estancia 100 (Rodríguez González y Celestino, 2017: 183) nos llevó a plantear los nuevos trabajos arqueológicos en el sector este del túmulo con el objetivo de conocer la funcionalidad del espacio que daba acceso a esta habitación de fuerte carga cultual (fig. 1). El planteamiento de la excavación nos permitió documentar dos espacios. El primero de ellos es un pequeño vestíbulo de sección trapezoidal con unas dimensiones aproximadas de unos $12,5 \mathrm{~m}^{2}$. Este espacio está separado de la estancia 100 por un acceso de tres escalones construidos con cuarcitas que posteriormente han sido enlucidos de arcilla naranja y forrados con finas lajas de pizarra hoy perdidas a causa del incendio generado en esta área del edificio.

El volumen de materiales arqueológicos documentados en este espacio no es abundante y, además, la mayor parte de éstos están afectados por el incendio que se produjo al final de la destrucción del edificio, pues varias de las ánforas documentadas habían estallado e incluso vitrificado por las altas temperaturas alcanzadas en este sector, lo que nos lleva a pensar que aquí debió concentrarse uno de los focos del incendio. A pesar de ello, cabe destacar la presencia de tres ánforas, cada una de ellas ubicada en sendos escalones que dan acceso a 

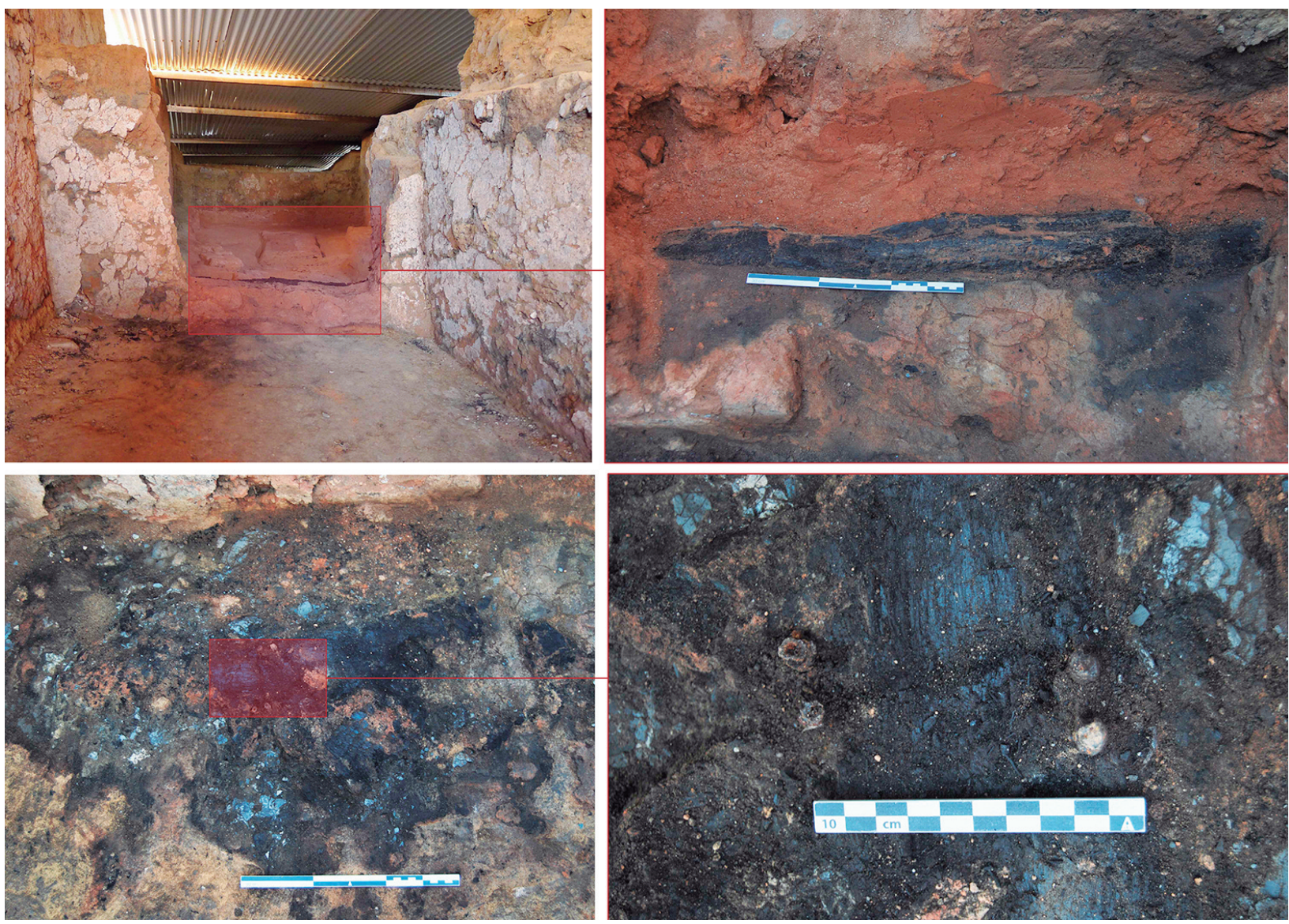

Figura 2. Vista de la puerta de acceso a la estancia del banquete desde el vestíbulo y los restos carbonizados documentados tras su excavación (izquierda). Fotografías de detalle de la viga que conforma el umbral de la puerta y de la conservación de los remaches de hierro clavados sobre el listón de madera carbonizada (derecha).

(Montaje: Carlota Lapuente. C) Construyendo Tarteso).

la estancia 100 , un brazalete de bronce y varias ofrendas de semillas, entre las que debemos reseñar la documentada en una pequeña urna de cerámica gris dentro de la cual todavía se conserva fosilizado parte de un saquito de lino donde posiblemente fueron contenidas las semillas (Marín Aguilera et al. 2019: 936; 938, fig. 3). A estos materiales hay que sumar la existencia de un telar del que han podido recuperarse un total de 43 pesas de sección circular y trapezoidal cuyo estudio, atendiendo a su peso, ha permitido conocer la existencia de dos grupos o medidas diferentes, lo que permitiría tejer diferentes tipos de tejidos (Marín Aguilera, et al. 2019: 939; Berrocal-Rangel et al.e.p.).

La excavación íntegra del vestíbulo permitió documentar la existencia de tres nuevos vanos que comunican esta pequeña área con sus respectivos espacios, uno al norte, otro al este y, un tercero, al sur. La elección del vano sur vino determinada por la aparición de parte de un timiaterio de trípode fabricado en bronce, fragmentado y muy afectado por la oxidación, hasta el punto de que una de sus patas no ha podido ser recuperada. Del timiaterio se conserva parte del vástago encargado de sostener la cazoleta donde serían quemadas las esencias y dos de sus patas, representadas por garras de león. Aunque la pieza no se conserva completa, las garras de felino nos permiten considerar que sus paralelos más cercanos se localizan en los ejemplares documentados en la tumba 17 de la necrópolis de La Joya (Garrido y Orta, 1970) y en el timiaterio de Villagarcía de la Torre, procedente de un contexto desconocido (de la Bandera y Ferrer, 1994). Finalmente, por el lugar en el que se realizó el hallazgo del quemaperfumes nos inclinamos a pensar que éste tuvo su posición original frente a la jamba izquierda de la puerta que da acceso a la estancia sur, dado que se trata de la jamba de mayor anchura.

Junto al timiaterio pudo recuperarse un conjunto de listones y vigas de madera que posiblemente procedan tanto de la techumbre que cubría el acceso a la estancia sur, como de la puerta de madera que debía existir en el vano que comunica la estancia con el vestíbulo. La hipótesis que sostiene la existencia de 
una puerta fabricada con listones de madera se basa en la aparición de cuatro remaches de hierro documentados in situ en uno de los listones, cuya función consistiría en fijar o unir las tablas que conforman la puerta. Así mismo, el zócalo de la puerta conserva in situ el listón de madera que define el umbral, donde se distingue la presencia de una quicialera en el extremo izquierdo de la misma (fig. 2).

Los análisis efectuados a un lote de los carbones localizados junto a la puerta, un total de 10 muestras, nos permite apuntar que la especie vegetal empleada en la construcción de los techos y entramados de esta área del edificio es el Pinus sylvestris, cuya madera puede considerarse de excelente calidad tanto para su uso en construcción y carpintería como para ser empleada como combustible ${ }^{3}$.

Esta puerta divide dos espacios, separando el vestíbulo de la estancia $S-1$, comúnmente bautizada como estancia del banquete debido a los materiales arqueológicos recuperados durante su excavación. Nuestro trabajo se centra en el análisis material y arquitectónico de este ámbito donde hasta la fecha se ha recuperado el mayor elenco de materiales relacionados con la preparación y celebración de un banquete, hasta el punto que tanto la cerámica recuperada como el conjunto de piezas metálicas pueden considerarse un ejemplo único dentro de la protohistoria del suroeste peninsular.

\section{LA ESTANCIA DEL BANQUETE}

El acceso a la estancia se realiza por un vano de 1,68 $\mathrm{m}$ de luz, enmarcado por dos jambas que dibujan una puerta de $1,08 \mathrm{~m}$ de anchura. La estancia tiene forma cuadrangular y una superficie de 20,4 $\mathrm{m}^{2}$ (fig. 3 a y b). El acceso norte no es el único con el que cuenta este espacio, pues se han documentado dos más: uno al oeste, de 2,37 m de luz, que comunica con una estancia paralela a la habitación 100; y otro al este, con $1,45 \mathrm{~m}$ de luz, que parece conectar la estancia con uno de los pasillos perimetrales que bordean el patio. La presencia de tres accesos en la estancia nos lleva a pensar que esta habitación no debió funcionar como una estancia privada sino como un espacio comunitario de redistribución o zona de paso que, como el vestíbulo descrito con anterioridad, comunica diferentes ámbitos.

En el muro este, a 1,40 m de altura con respecto al nivel del suelo, se conserva un vano de 1,25 $\mathrm{m}$ de anchura. Su base está construida con losas de arcilla, idénticas a las documentadas en el ámbito 1 de la habitación 100 (Rodríguez González y Celestino, 2017: 183). Lamentablemente la estructura no se conserva completa, pues estaba alterada por la presencia de una fosa medieval colmatada con piedras y cenizas que nos impide conocer la terminación del hueco por el este; sin embargo, dada la dirección e inclinación que presenta, parece que comunicaría la estancia con el patio. De ese modo, si tenemos en cuenta la altura a la que se encuentra y el hecho de que comunique con un espacio abierto, podemos interpretar este vano como una posible ventana que se encargaría de ventilar la habitación e iluminar el acceso que esta estancia tiene en su muro oeste (fig. 3c), hasta la fecha el vano de mayor

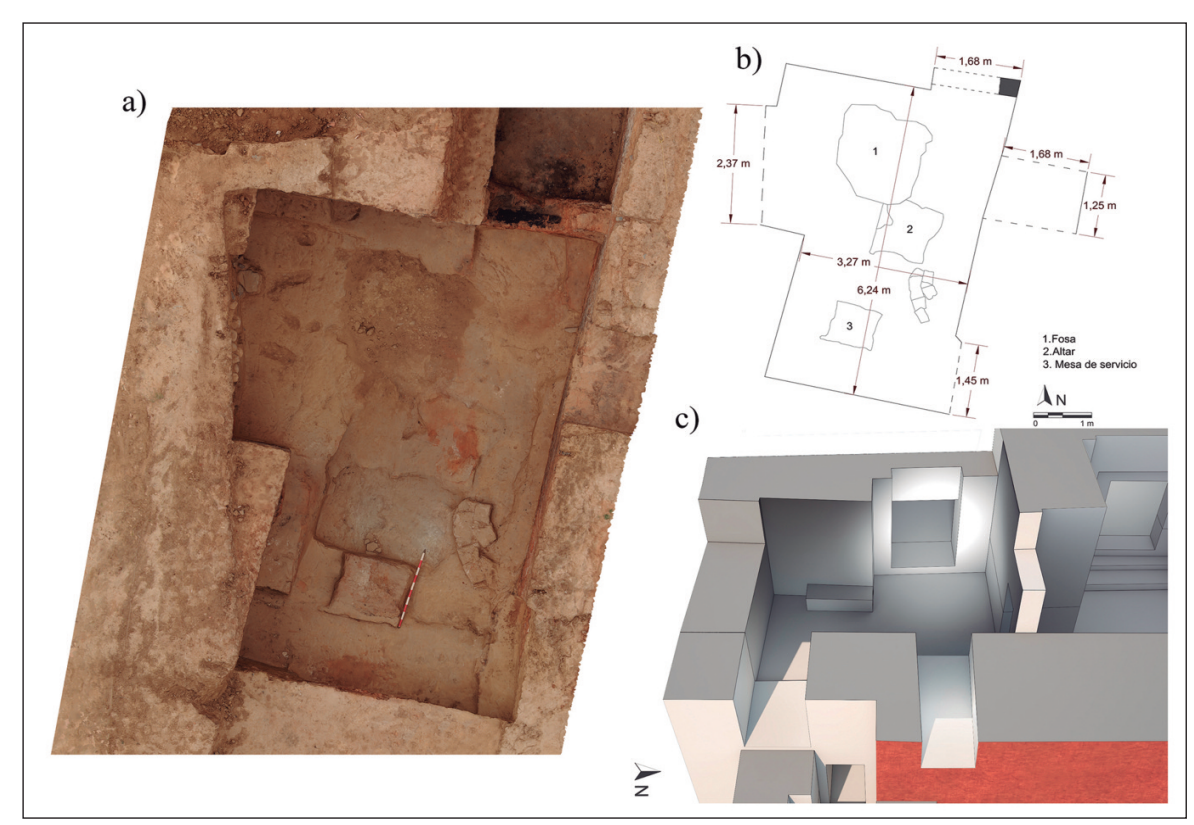

Figura 3. A) Fotogrametría de la estancia S-1. B) Planimetría de la estancia S-1. C) Reconstrucción $3 D$ de la ventana presente en el muro este de la estancia. A la imagen se le ha aplicado un foco de luz para ilustrar la iluminación del vano oeste. (Diseño: a y b: Carlota Lapuente; : Josep R. Casals. (C) Construyendo Tarteso).

3 Análisis realizado por Mónica Ruíz Alonso en el Laboratorio de Arqueobiología del CCHS del CSIC. 
anchura documentado en el edificio. En el antepecho de la ventana se recuperó un lote de materiales compuesto por un jarro de bronce, varios cuchillos afalcatados y un pico, fabricados en hierro, así como un recipiente de cerámica de grandes dimensiones, elaborado a mano y que tiene como asas dos orejetas en forma de herradura en cuyo interior se recuperó una fusayola (fig. 9a TU/17/510/100).

La construcción de la estancia se realizó siguiendo el mismo patrón arquitectónico que el documentado en la estancia 100: alzados de adobe que se cubren por una capa de arcilla naranja que posteriormente se decora con un espeso enlucido blanco. Aunque está pendiente realizar un muestreo de todos los enlucidos presentes en cada uno de los muros que conforman las estancias del edificio, los análisis preliminares realizados sobre algunos fragmentos desprendidos de los enlucidos de la estancia 100 nos han permitido determinar que estas decoraciones se realizan mediante la aplicación de caolines (Martín Sánchez et al. 2019), el mismo sistema que el empleado en los enlucidos documentados en los vecinos yacimientos de Cancho Roano (Zalamea de la Serena) (Celestino, 2001: 72) y La Mata (Campanario) (Ponce de León, 2004: 331); sin embargo, la constatada presencia del uso de la cal en la construcción del edificio nos lleva a sospechar que ambos materiales se están empleando en la decoración de los muros.
La conservación de los alzados de la estancia es irregular, pues este espacio se ubica en la ladera sur del túmulo, de tal manera que cuanto más nos acercamos a su límite menor es la altura del alzado preservada. De ese modo, las alturas conservadas para los muros oeste, este y norte oscila entre $1,80 \mathrm{~m}$ y $1,96 \mathrm{~m}$, mientras que del muro que delimita la estancia al sur apenas se conservan $0,88 \mathrm{~m}$ de altura.

A nivel arquitectónico uno de los elementos más destacados y que mayor interés despierta es la conservación del pavimento. Durante la excavación de la estancia 100 tuvimos ocasión de comprobar la irregularidad con la que éstos han llegado hasta nosotros, hasta el punto de que han perdido por completo su horizontalidad, presentando dentro de un mismo espacio diferentes alturas o cotas. Este hecho resulta llamativo si tenemos en cuenta la calidad arquitectónica y técnica que presenta el resto de la construcción, por lo que contrasta con la escasa calidad de sus pavimentos. Así mismo, si la irregularidad de los pavimentos ya se constataba en la estancia 100, en la zona que nos ocupa es mucho más acentuada, tanto en el vestíbulo como en la "estancia del banquete", donde los suelos de arcilla apisonada aparecen completamente descolgados de los alzados de adobe, con desniveles que alcanzan en algunos puntos hasta el medio metro de altura.

Hasta que completamos en el año 2017 la excavación del patio localizado al este del vestíbulo, desco-

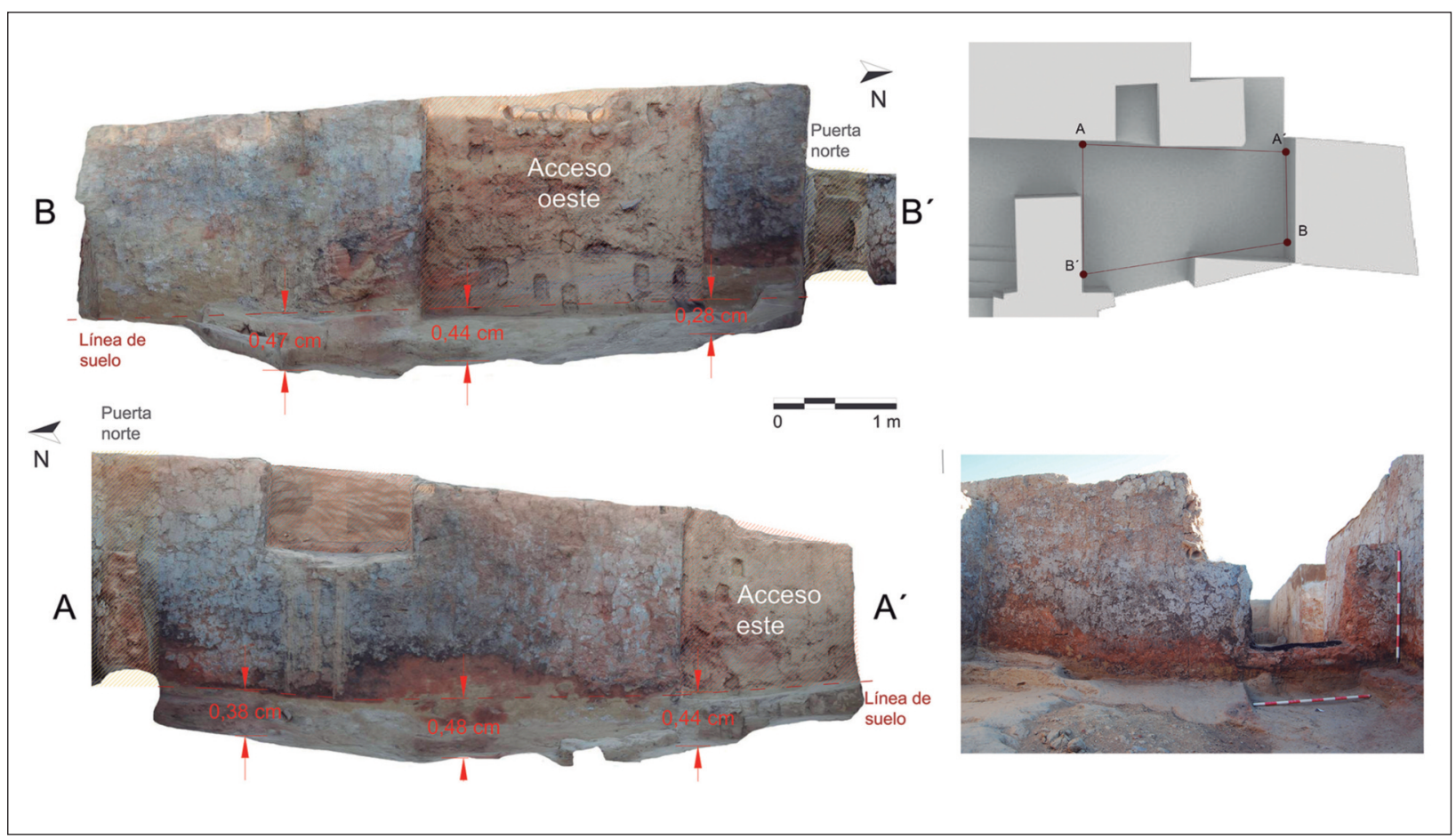

Figura 4. Fotogrametría de los alzados oeste y este de la estancia $S-1$ en los que se ilustra el hundimiento del suelo con respecto a su línea original. (Montaje: Carlota Lapuente. (C) Construyendo Tarteso). 


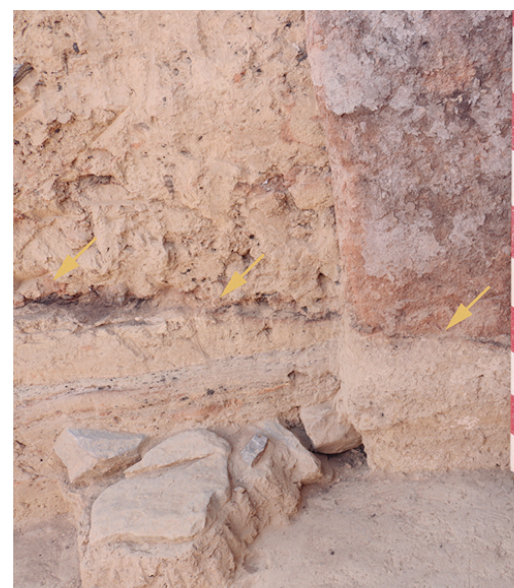

A)

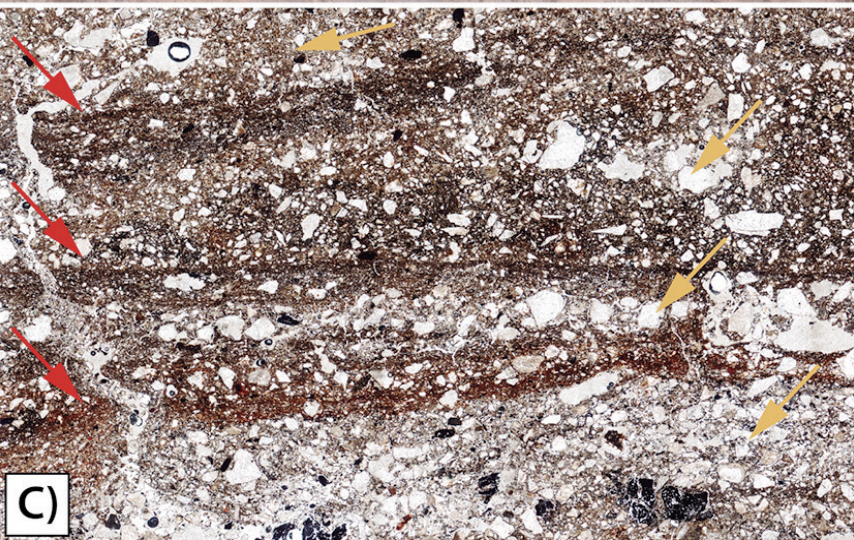

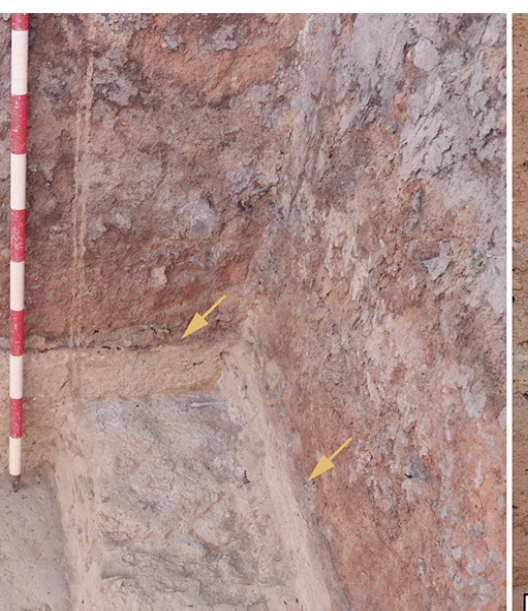

B)

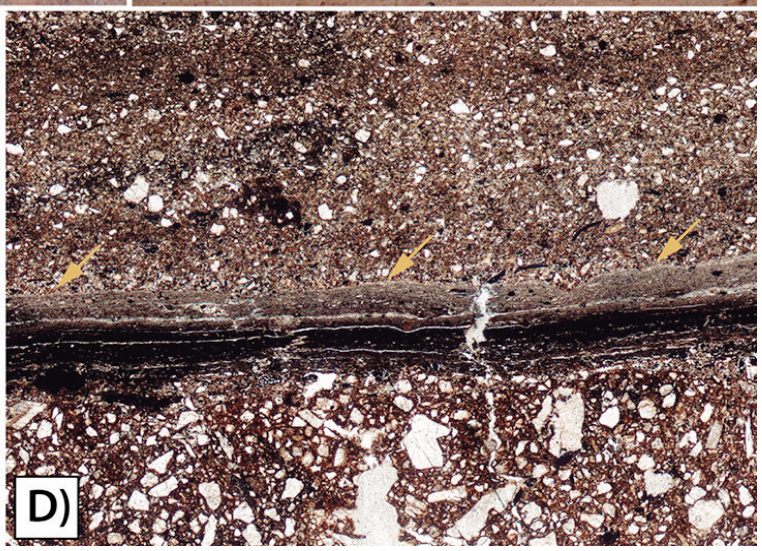

Figura 5. A) Secuencia microestratificada bajo la cota de afección del incendio final del Turuñuelo (bajo flechas naranjas); B) Detalle de la secuencia microestratificada, donde se superponen de manera horizontal varias decenas de depósitos que alternan arcillas arenosas, limos y cenizas ricas en carbones; C) Pavimentos de tierra batida (flechas rojas) y subproductos de las actividades asociadas a esos pavimentos (flechas naranjas);

D) Tejido carbonizado - ¿alfombra, cortina?- (flechas naranjas). (Producción: Mario Gutiérrez. OConstruyendo Tarteso).

nocíamos que tanto la Estancia 100 como la "estancia del banquete" se localizan en el piso superior del edificio. Esta localización, sumada a la mala colmatación de las estancias inferiores, han provocado la alteración de los pavimentos y su hundimiento, un hecho que ya fue puesto de manifiesto durante las excavaciones de la estancia 100 (Rodríguez González y Celestino, 2017: 186), donde llamaba la atención la ausencia de suelos de calidad, semejantes a los documentados en otros yacimientos coetáneos como Cancho Roano o La Mata. Mientras en el caso de la estancia 100 las irregularidades detectadas en su pavimento son mucho más heterogéneas, pues un mismo suelo presenta diferentes rehundimientos en distintos puntos de la superficie, tanto en el vestíbulo como en la "estancia del banquete", el vencimiento de los suelos se acentúa en la parte central, con desniveles que alcanzan casi el medio metro de profundidad (fig. 4), lo que supone un descuelgue muy acentuado. Esta circunstancia ha afectado a la posición e integridad de algunos elementos arquitectónicos secundarios, principalmente en el caso de la "estancia del banquete", donde los hogares presentan una inclinación hacia el centro de la estancia bastante pronunciada; al mismo tiempo nos ha permitido reconstruir las diferentes fases constructivas. Así, por ejemplo, al haberse descolgado los suelos, los alzados que quedan a la vista carecen de decoración alguna por tratarse del espacio que quedaba oculto por el grosor del suelo que separa ambas plantas.

Para completar el estudio estratigráfico del pavimento y apurar los conocimientos acerca de las actividades desarrolladas en esta estancia, hemos emprendido su análisis microestratigráfico (fig. 5a). En él puede observarse la superposición horizontal de varias decenas de depósitos que alternan arcillas arenosas, limos y cenizas ricas en carbones (fig. 5b). Estos depósitos son el resultado de una ocupación continua del sitio y de la realización de diferentes 
actividades en la estancia. Actualmente, se está llevando a cabo un análisis geoarqueológico de alta resolución que combina diferentes técnicas analíticas con el fin de identificar los procesos de formación del registro arqueológico, tanto antrópicos como naturales, involucrados en la génesis de esta secuencia microestratificada ${ }^{4}$. Entre las técnicas empleadas destacan la micromorfología de suelos y sedimentos arqueológicos, análisis físicoquímicos y geoquímicos. Los resultados preliminares han caracterizado esta secuencia como un palimpsesto de episodios de reflooring o repavimentación. Así, se superponen distintos pavimentos de tierra batida alternando colores muy vivos (rojo, amarillo y blanco) con apenas uno o dos milímetros de espesor (fig. 5c, flechas rojas). Sobre estos pavimentos se localizan los subproductos de las diferentes actividades llevadas a cabo en la estancia a lo largo de su existencia (fig.5C, flechas naranjas). Entre estos depósitos destacan los compuestos de forma casi exclusiva por cristales romboidales de cenizas calcíticas, carbones y grasa animal o vegetal carbonizada, lo que sugiere que el espacio estuvo destinado al cocinado de los alimentos y a la comensalidad. Además, se han identificado tejidos carbonizados in situ sobre los pavimentos de tierra batida (fig.5d). Todo ello indica que el estudio actualmente en vías de desarrollo será clave en la caracterización de los usos del espacio, así como la naturaleza de las actividades desarrolladas en el asentamiento de forma diacrónica, lo que a la postre proporcionará una secuencia del asentamiento a escala microestratigráfica que para el caso de la estancia sur parece indicar una intensa repetición de rituales de comensalidad de forma periódica.

A la mala conservación del pavimento también ha contribuido la ejecución de una fosa de forma irregular en el centro del sector norte de la estancia. La excavación de la fosa destruyó el pie derecho donde iría inserta la viga documentada en el centro de la estancia, la encargada de sostener la techumbre plana de este espacio, así como parte de uno de los hogares localizados en la misma. La fosa tiene una planta de aparente forma triangular con sus ángulos redondeados. Esta irregularidad en la forma nos ha permitido documentar unas dimensiones de 1,07 $\mathrm{m}$ de ancho en su lado menor y 1,54 $\mathrm{m}$ de anchura en su lado mayor; mientras que su largo es de aproximadamente 1,76 m. Descono- cemos la profundidad de la misma, pues no agotamos su estratigrafía por temor a mezclar el material de relleno de la fosa con el relleno de la estancia inferior. De ese modo, y con el objetivo de no mezclar materiales procedentes de dos actividades y ámbitos distintos, a la profundidad de algo más de metro y medio, detuvimos la excavación de la fosa con la finalidad de acometerla cuando esté diseñada la metodología de intervención para las estancias inferiores.

Los materiales arqueológicos recuperados del interior de la fosa nos invitan a pensar que fue excavada para ser usada como basurero durante la celebración del banquete. De su interior se han recuperado un lote de piezas de hierro, actualmente en fase de restauración, y un conjunto de restos cerámicos, platos y cazuelas fundamentalmente, empleadas en el banquete. Entre estas últimas llama la atención un cuenco carenado de labio abierto, fabricado a torno y cocido en ambiente oxidante de una excepcional calidad. La cazuela tiene una decoración acanalada en la parte central de su sección, cuyos espacios han sido decorados mediante finas líneas incisas verticales, al igual que el interior de su labio (fig. $10 \mathrm{~b}-$ TU/16/522/67). Por último, del interior de la fosa pudo recuperarse un lote de fauna, actualmente en fase de estudio y publicación, entre la que se distinguen especies domésticas y restos fruto de la actividad cinegética.

Junto a la fosa, en su extremo este, se localiza uno de los dos hogares (UE 529) presentes en la estancia. Su estado de conservación es deficiente, pues además de estar seccionado en su extremo oeste por la ejecución de la fosa, se encuentra completamente inclinado hacia el centro de la estancia como consecuencia del hundimiento del suelo (fig. 6a). La estructura está fabricada a partir de dos losas de adobe naranja separadas por una pequeña junta de arcilla amarilla. Aunque conserva unas medidas de $0,98 \times 0,96 \mathrm{~m}$, cabe suponer que estaría fabricado con losas de $0,55 \mathrm{~m}$, pues se trata de las medidas de una de las cajas empleadas para la fabricación de los adobes utilizados en la construcción del edificio (Rodríguez González y Celestino, 2017: 183). Su uso durante la celebración del banquete queda bastante claro ante la presencia de abundantes cenizas sobre la base del mismo.

El segundo hogar (UE 526) se localiza en el centro del extremo sur de la estancia (fig. 6b). Su

\footnotetext{
4 Análisis realizados por Mario Gutiérrez en los laboratorios de Prehistoria y Arqueología de la Universidad de Granada y el School of Archeology and Ancient History de la Universidad de Leicester.
} 

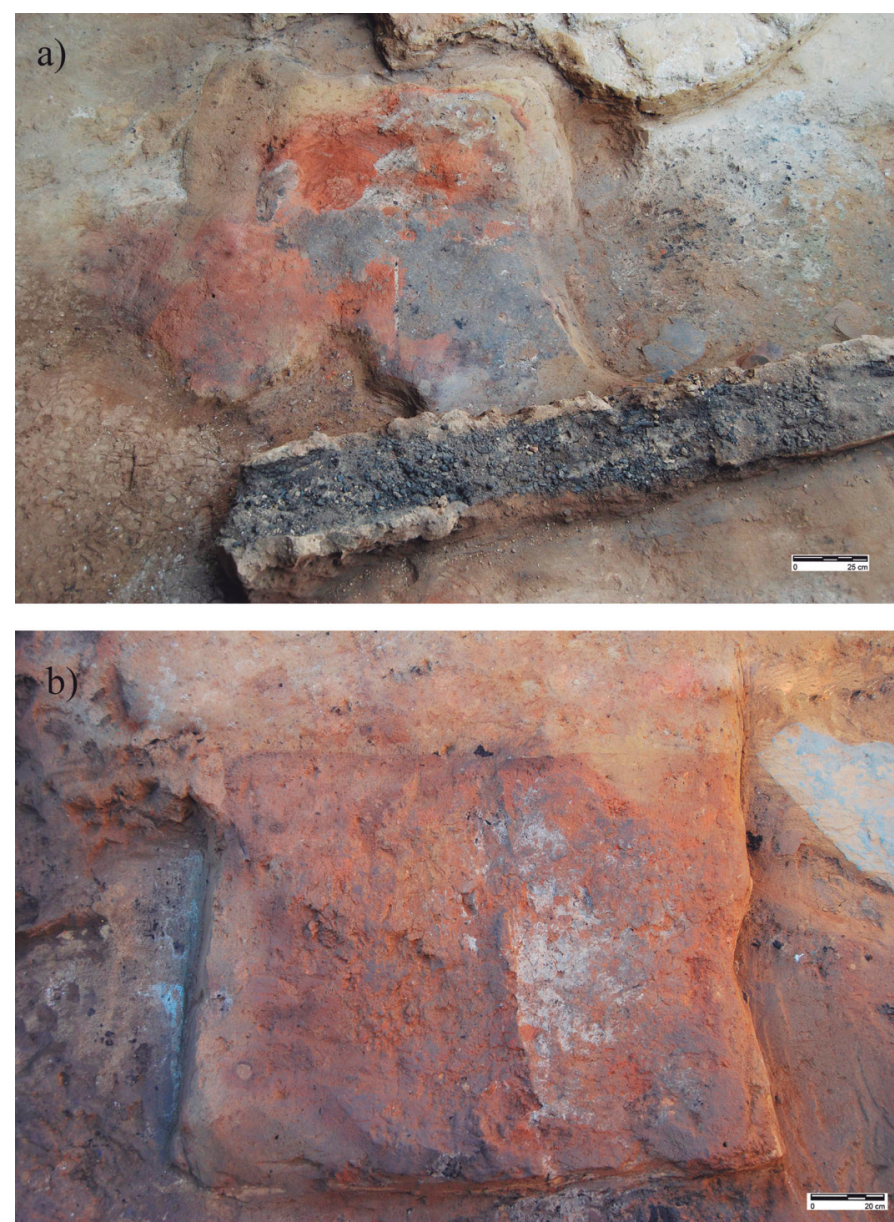

Figura 6. A) Fotografía de detalle del altar en forma de piel de toro (UE 529). B) Fotografía de detalle de la “mesa de servicio" (UE 526). (Montaje: Carlota Lapuente. (C) Construyendo Tarteso).

estado de conservación es bueno, aunque también se encuentra ligeramente inclinado hacia el centro de la estancia como consecuencia del hundimiento de la misma. Conserva unas medias de $0,75 \times 0,75$ $m$ y está diseñado siguiendo el mismo esquema que el anterior, a partir de dos adobes naranjas de 0,55 $\mathrm{m}$ de lado, separados por una pequeña junta de arcilla amarillenta. Tanto su base como su entorno estaban completamente colmatados de cenizas, siendo éstas más abundantes en el extremo norte.

A pesar de las similitudes que a primera vista guardan sendas estructuras, existen claras diferencias entre ambas. La primera de ellas compete a su diseño. Mientras la segunda estructura respeta su forma rectangular, el primer hogar (UE 529) posee sus lados cóncavos y apéndices en las esquinas, lo que le da una aparente forma de piel de toro. Esta diferencia nos lleva a plantearnos la siguiente pregunta, ¿fueron empleadas ambas mesas para la misma actividad?
A la diferencia que existe en el diseño de ambas estructuras se suma la orientación que presentan, pues mientras la estructura 526 está orientada norte-sur, el hogar 529 está orientado en sentido este-oeste, es decir al naciente solar, un aspecto que esta estructura comparte con el altar de la estancia 100 (Rodríguez González y Celestino, 2017: 184), así como con el resto de altares taurodérmicos documentados en el territorio de Tarteso, caso de El Carambolo o Coria del Río (Escacena e Izquierdo, 2010: 27; Gómez Peña, 2017). Pero todavía podemos ir un poco más allá en la identificación de la funcionalidad de ambas estructuras; así, mientras el entorno del hogar (UE529) estaba completamente limpio, el pavimento que rodea a la mesa (UE 526) contaba con abundantes restos de desechos orgánicos, destacando, junto a la presencia de restos óseos, una abundante acumulación de conchas e improntas de bellotas, resultado de su cocinado y consumo junto a la estructura.

Todos estos indicios nos permiten interpretar la estructura 529 como un altar en forma de piel de toro destinado a la realización de sacrificios en el marco del ritual celebrado al final de la vida del edificio; mientras que la estructura 526 debe ser entendida como una "mesa de servicio" en la que se han preparado los alimentos consumidos durante el banquete celebrado antes de la clausura y abandono de la construcción. Por último, los restos del sacrificio fueron depositados en el interior de la fosa que se practicó en el suelo de la estancia justo frente al altar.

Los elementos arquitectónicos secundarios se completan con dos estructuras de compleja interpretación que están adosadas, respectivamente, a los muros oeste y este de la estancia. La estructura UE 524 posee una forma rectangular y conserva unas dimensiones de 1,65 x 0,50 m. Su proximidad a la "mesa de servicio" y su relación directa con el lote de materiales cerámicos recuperados en la estancia y que serán analizados a continuación, nos llevan a interpretarlo como un pequeño poyete o mesa para depositar los objetos empleados en el tratamiento y consumo de los alimentos. La segunda estructura se encuentra completamente destruida, de ahí la complejidad para determinar su uso. Se trata de una acumulación de adobes de sección cuadrangular sobre la que se recuperó un lote de materiales cerámicos, principalmente platos. La excavación de la estructura nos permitió documentar una espesa capa de pizarras descompuestas que posiblemente decoraban la estructura, 


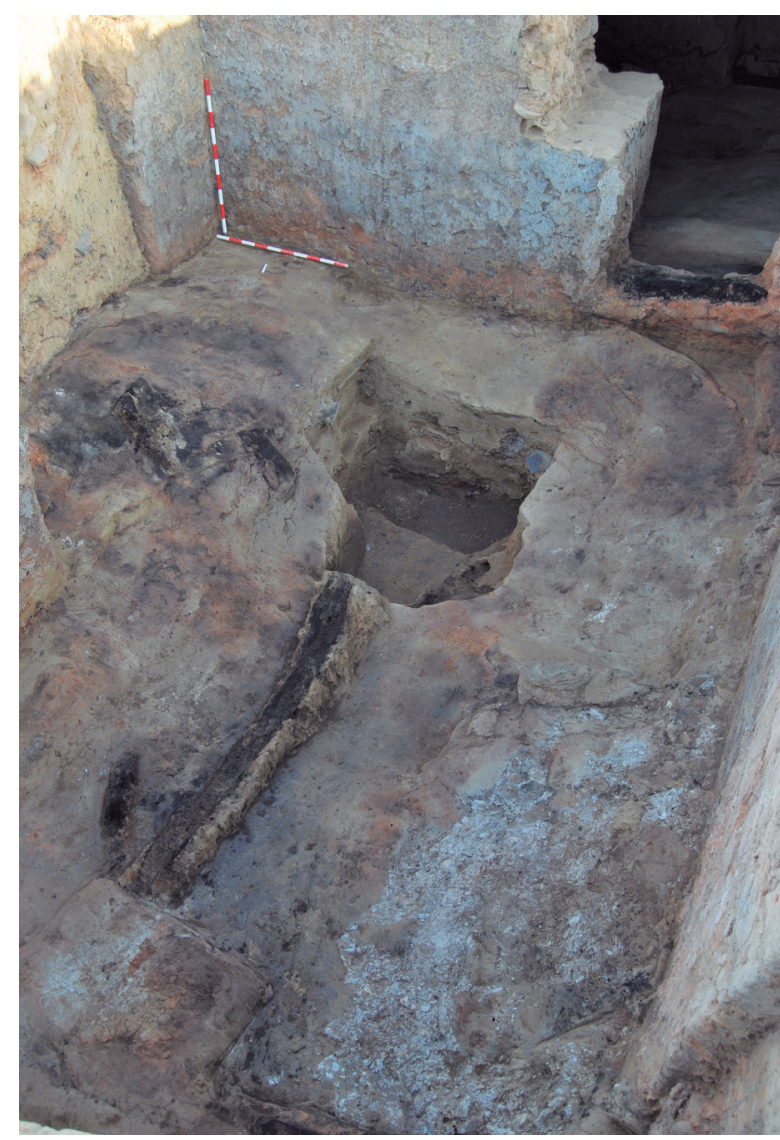

Figura 7. Vista desde el sur de la estancia S-1 donde puede observarse la fosa practicada en el suelo de la estancia y la viga correspondiente al poste central donde se sostendría la techumbre (CConstruyendo Tarteso).

un ejemplo que ha sido detectado en otros elementos arquitectónicos del yacimiento como el pedestal sobre el que se dispone la bañera o el banco corrido de la estancia 100 (Rodríguez González y Celestino, 2017: 185 y 186). Sin embargo, la disposición que presentan los adobes no posee una forma aparente, lo que complica su interpretación. Dada la posición que posee la estructura y los materiales a ella asociados, solo cabe pensar que se trate de una segunda mesa relacionada con las actividades rituales desarrolladas en esta estancia. Posiblemente, la inclinación que el suelo presenta hacia el centro de la estancia ha favorecido el deslizamiento de los adobes, rompiendo la forma original que tendría la estructura.

A diferencia de la estancia 100, donde las dimensiones del espacio nos han obligado a plantear una alternativa a la tradicional cobertura plana con la que cuentan este tipo de construcciones, la modalidad de techumbre empleada para cubrir la estancia del banquete parece bastante clara. Dado que la habitación supera los tres metros de anchura, lo que complica el diseño de una cubierta plana realizada con vigas de pared a pared, la estructura necesita de un pilar central que actúe de apoyo, pilar que pudo documentarse sobre el pavimento de la estancia, junto a restos de fragmentos de viga y ramajes. Se trata de una viga carbonizada de 1,94 m de largo (fig. 7), posiblemente fabricada con madera de pino, la misma especie que la empleada para la techumbre del acceso norte de la estancia cuyos restos ya han sido analizados. De ese modo, podemos sostener que la estancia estuvo cubierta por una techumbre plana construida con vigas transversales y ramajes que se impermeabilizaron mediante su cubrición con barro. Este sistema está atestiguado en oriente en los ámbitos domésticos fenicios (Díes Cusí, 1994), así como en enclaves de cronología tartésica, como en el vecino Cancho Roano (Celestino, 2001b).

\section{COCINAR, SERVIR Y DEGUSTAR: EL ELENCO MATERIAL DE LA "6STANCIA DEL BANQUETE"}

A pesar de sus pequeñas dimensiones, la estancia S-1 es, hasta la fecha, uno de los espacios más ricos a nivel material del yacimiento de Casas del Turuñuelo. De las excavaciones de este espacio han podido recuperarse un rico conjunto de objetos entre los que destacan las cerámicas y las piezas de metal, de excepcional calidad. El elevado número de piezas recuperadas no nos permite abordar por completo su estudio dentro de este trabajo, una labor que quedará para la futura publicación de la memoria de excavación; sin embargo, recogeremos en las próximas páginas una síntesis del ajuar recuperado y su estrecha relación con la existencia de un contexto de consumo traducido en la celebración de un suntuoso banquete al final de la vida del edificio.

La dispersión del material dentro de la estancia y el análisis estratigráfico de su localización es bastante clara, hasta el punto que nos ha permitido, como ya aludíamos, diferenciar la realización de dos actividades distintas: el cocinado de los alimentos y su posterior consumo. De ese modo, los restos del banquete aparecen depositados en dos niveles distintos, concentrándose la cerámica de almacenamiento y cocina en las unidades correspondientes a la fosa y el pavimento; mientras que la vajilla de lujo aparece agrupada en la denominada UE 511, concretamente en la esquina suroeste de la habitación, en coincidencia con la ubicación de uno de los bancos o poyetes y la "mesa de servicio" donde se llevó a cabo la preparación de algunos alimentos. Se trata de una unidad de 
relleno de tonalidad amarilla y gran dureza que cubre directamente el suelo de la estancia. El material recuperado dentro de dicha unidad, aunque muy fragmentado, se encontraba completo, por lo que el lote ha podido ser reconstruido casi en su totalidad, lo que con seguridad nos permitirá conocer la actividad desarrollada en este espacio justo antes de su clausura (fig. 8).

\section{1- La vajilla cerámica}

Como suele ser habitual en cualquier yacimiento arqueológico, el mayor volumen de material corresponde a las cerámicas, de las que se ha podido recuperar un interesante y completo lote. Diferenciar los tipos de recipientes presentes en la estancia resulta de vital importancia para abordar la correcta interpretación funcional de la habitación, pues a pesar de que los objetos nos marcan la existencia de un momento de preparación de los alimentos y un período de consumo de los mismos, las dimensiones de la estancia y la localización de todos los ejemplares nos permiten definir con claridad el uso que se le dio a la misma, un uso cuya definición final quedará perfilada en un futuro, cuando se desarrollen las excavaciones de la habitación ubicada al oeste de la estancia del banquete, cuya importancia ya ha sido remarcada en la lectura arquitectónica de este espacio.

De ese modo, el estudio estratigrá-

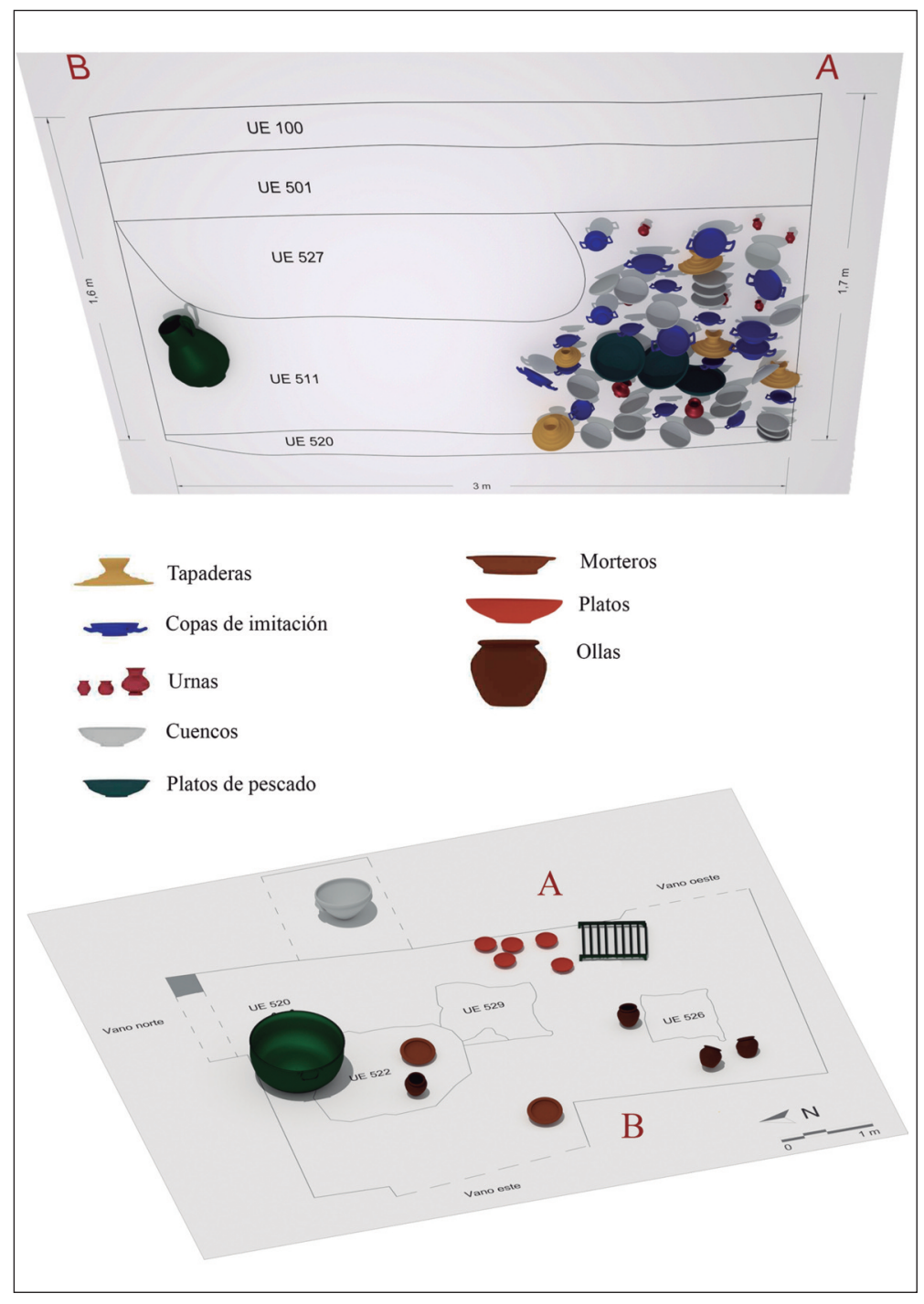

Figura 8. Sección estratigráfica y planimetría de la estancia $S-1$ donde se ilustra la ubicación de los restos materiales hallados durante las excavaciones de la misma. (Diseño: Carlota Lapuente. (C) Construyendo Tarteso). fico y tipológico de las formas cerámicas presentes en la habitación nos ha permitido distinguir tres grandes grupos cerámicos: los recipientes de cocina, los de almacenaje y el servicio de mesa.

La cerámica de cocina se concentra en las unidades correspondientes al pavimento de la estancia y la fosa en la que fueron vertidos los desperdicios de la preparación de los alimentos y los sacrificios realizados en el altar de la estancia. Sus formas han experimentado menos cambios en el tiempo, perdurando incluso la tradición de fabricarlas a mano, dada su mejor resistencia al choque término durante su contacto directo con el fuego, y cocerlas en ambientes reductores; aunque dado que muchos de los recipientes estaban destinados a la preparación de alimentos en caliente, es decir, que estuvieron en contacto directo con el fuego, las tona-

lidades de sus pastas tienden a ser muy irregulares. Así, la homogeneidad en el repertorio hace que los tipos se encuentren bastante extendidos por todo el suroeste peninsular, lo que complica la definición de tipologías; no obstante, el repertorio recuperado en el yacimiento de Casas del Turuñuelo tiene su mejor paralelo en el grupo B, correspondiente a las cerámicas a mano toscas, del servicio recuperado en el yacimiento de La Mata (Rodríguez Díaz y Ortiz Romero, 2004: 223 - ss).

Entre los tipos de recipientes de cocina podemos diferenciar entre aquellos destinados a la preparación de alimentos en frío y los concebidos para su posterior cocinado y, por lo tanto, para estar en contacto con el fuego. Dentro del primer grupo se incluyen los morteros y grandes platos (fig. 9a), 
a)

\section{$\mathrm{TU} / 17 / 510 / 100$}

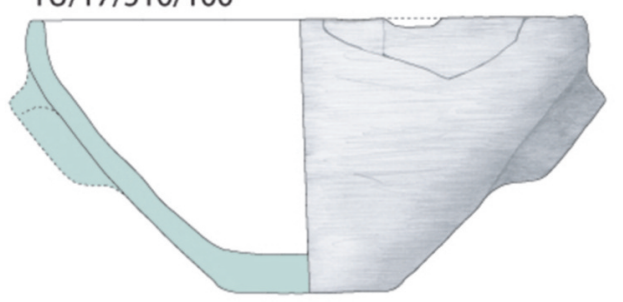

b)

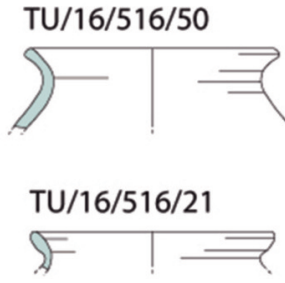

$\mathrm{TU} / 16 / 515 / 17$

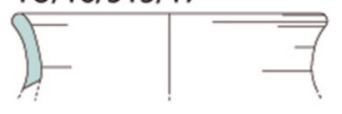

d) $\mathrm{TU} / 16 / 522 / 39$

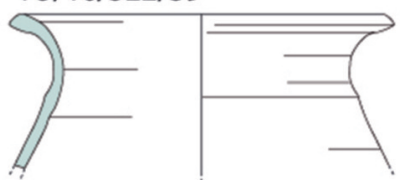

$\mathrm{TU} / 16 / 522 / 43$

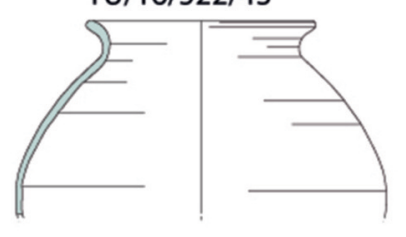

c)

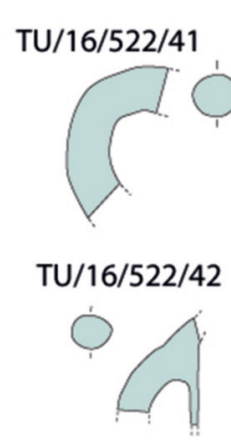

TU/16/522/46

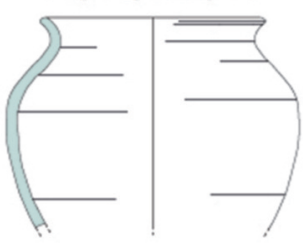

\section{TU/16/516/12}

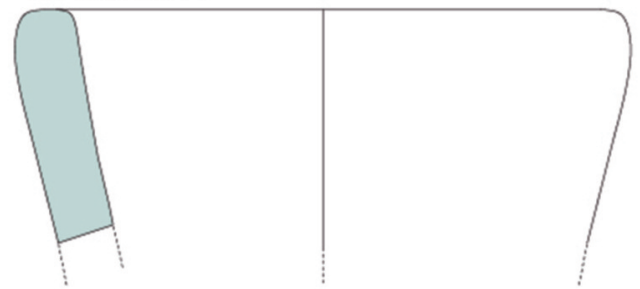

$\mathrm{TU} / 16 / 522 / 40$

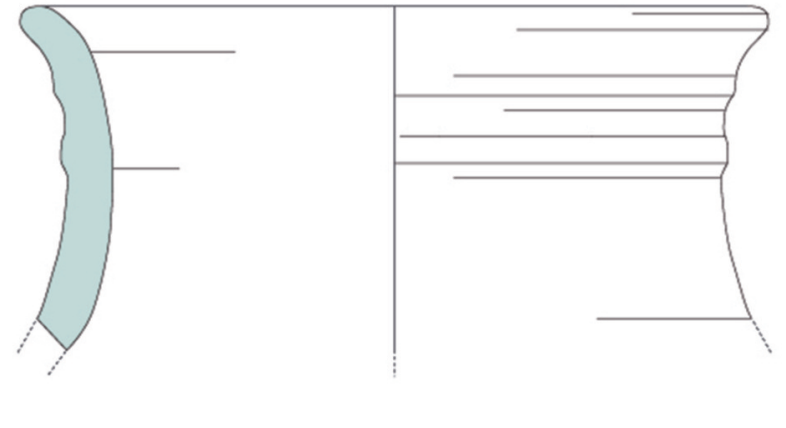

e)
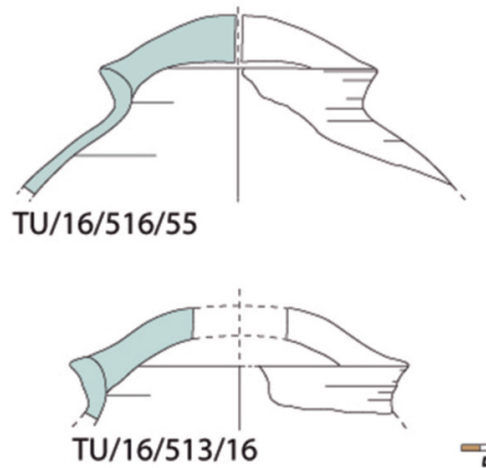

$5 \mathrm{~cm}$.

Figura 9. Selección de cerámica de cocina y almacenaje procedente de la estancia $S$-1 del yacimiento de Casas del Turuñuelo. (Dibujo: Sabah Walid. CConstruyendo Tarteso).

grandes recipientes de paredes gruesas con bordes muy desarrollados, destinados al amasado y la trituración de los alimentos (García Fernández y García Vargas, 2010: 123). Por su parte, son las cazuelas y las ollas las destinadas al preparado en caliente (fig. 9b). La diferencia entre ambos tipos está en sus perfiles. Mientras las ollas presentan una tendencia globular con los bordes abiertos al exterior, las cazuelas poseen bordes engrosados al interior, tipo almendrado, con la superficie plana, lo que le permite sostener una tapadera. Sus paredes tienden a ser más gruesas y toscas que en el caso de las ollas que, aunque también fabricadas a mano, presentan pastas más depuradas con desgrasantes de mediano y pequeño tamaño.

El segundo grupo cerámico está compuesto por los recipientes de transporte y almacenaje. De diferente tamaño y capacidad, el contenedor de transporte por antonomasia es el ánfora, principalmente por su capacidad de movilidad y su empleo en el intercambio de alimentos y líquidos. Aunque se ha recuperado un destacado número de ánforas en diferentes ámbitos del yacimiento de Casas del Turuñuelo, los restos recuperados en la estancia del banquete permiten distinguir la presencia de, al menos, dos de estos recipientes, pues no contamos con sus perfiles completos (fig. 9c). Un estudio reciente sobre las producciones de ánforas en el valle medio del Guadiana (Rodríguez González et al. e.p.) ha permitido determinar que la forma predominante en este territorio son los perfiles de saco, adoptados tras la colonización fenicia y presentes en este territorio sin experimentar importantes cambios formales hasta el siglo $\mathrm{V}$ a.C. Por lo 
tanto, y a diferencia de las formas documentadas en el valle del Guadalquivir, las producciones del Guadiana presentan una gran homogeneidad, experimentando cambios únicamente en sus bordes, lo que ha sido traducido en una estandarización de las formas fruto de la existencia de un comercio a pequeña escala que no necesitó de la evolución de sus contenedores de transporte.

Junto a las ánforas destacan las urnas, de compleja clasificación dado su carácter polifuncional (García Fernández y García Vargas, 2010: 123; Ferrer y García Fernández, 2008: 211), lo que en ocasiones complica la tarea de determinar su uso; sin embargo, su forma cerrada la convierte en un excepcional recipiente para el almacenaje a corto y medio plazo. La diversidad en su uso hace que sea uno de los recipientes más representados, como puede observarse en enclaves del Guadiana Medio como La Mata (Campanario), de donde procede un destacado conjunto cuyo estudio permite determinar la homogeneidad y estandarización de sus formas, razón por la cual su clasificación se ha realizado atendiendo a su calidad técnica (Rodríguez Díaz y Ortiz Romero, 2004). Dentro de este grupo cerámico, en la estancia del banquete del yacimiento de Casas del Turuñuelo podemos diferenciar, a grandes rasgos, dos tipos: las urnas globulares o bitroncocónicas (fig. 9d), de bordes exvasados y cuellos abocinados; y las urnas con asa de cesta a las que se supone un uso para el almacenamiento y transporte interno de los alimentos o ingredientes. Este tipo de urnas han sido también documentadas en los yacimientos de La Mata (forma 3.d.e) y Cancho Roano, mientras que los ejemplares de mayor calidad del Turuñuelo han sido localizados en el vestíbulo que da acceso a la estancia (fig. 9e).

El último grupo cerámico corresponde al servicio de mesa, destinado al consumo de bebidas y alimentos. Como apuntábamos, el lote recuperado de la estancia del banquete procede de la UE 511 , un nivel de relleno ubicado justo por encima del pavimento (fig. 8), lo que sitúa a este conjunto fuera de un contexto de uso. Este dato resulta de gran interés si además tenemos en cuenta que el material se localizaba en un punto concreto de la estancia, donde parece que tras la celebración del banquete fue depositado junto a otros elementos de metal empleados en el ritual. Del lote recuperado pueden destacarse dos aspectos: por un lado, la diversidad de recipientes, pues el conjunto reúne todas las formas cerámicas presentes en la vajilla de mesa, desde los vasos y las copas para beber, hasta los cuencos, platos y fuentes, así como las tapaderas, lo que nos permitirá en un futuro reconstruir los hábitos culinarios y alimenticios del yacimiento. Por otro lado, debemos destacar la calidad técnica de las producciones, donde se observa la presencia de pastas muy depuradas con desgrasantes muy finos, cocidas en ambientes oxidantes y con cuidados acabados, entre los que destacan las superficies decoradas con engobe o pintadas a bandas que permiten emparentar a este repertorio con los típicos conjuntos de tradición turdetana del Bajo Guadalquivir.

La comúnmente denominada como cerámica turdetana es considerada como el resultado de la "hibridación selectiva" entre la tradición local y la oriental llegada con el proceso de colonización cuyos tipos se estandarizan en el s. V a.C. y perduran, aunque con algunos cambios que atañen a la simplificación de las decoraciones, prácticamente hasta la romanización (García Fernández, 2007: 130; 2014: 209). La homogeneidad del repertorio ha llevado a suponer que la aparición de variantes es el resultado de la convivencia entre diversos talleres que, aunque comparten unos mismos parámetros productivos y tecnológicos, dotan de personalidad a sus repertorios cerámicos (García Fernández y Sáez Romero, 2012: 111112). Como veremos a continuación, esta es la realidad que se desprende tras analizar el servicio de mesa documentado en la estancia del banquete, donde junto a producciones arraigadas en el Bajo Guadalquivir existen imitaciones fabricadas en el propio yacimiento.

Una de las formas más numerosas, pues están presente tanto en el relleno como sobre el suelo de la estancia, son los platos y cuencos de casquete esférico (fig. 10a). La pluralidad en la presencia y los acabados que presentan estas formas está posiblemente relacionada con su funcionalidad, pues muy probablemente se están empleando tanto para el preparado como para el consumo de los alimentos. Dada la diversidad encontrada en el yacimiento de Casas del Turuñuelo en lo que a platos y cuenco se refiere, la diferenciación tipológica entre ambos requerirá de un estudio detallado de las formas a partir de la enorme cantidad de recipientes recuperados.

Hasta el momento, los tipos aparecen diferenciados por sus bordes, hasta seis variantes, pues poseen regularidad tanto en su perfil, de casquete esférico a excepción de algún ejemplar con carena, como en sus bases, de tendencia plana o con el pie ligeramente desarrollado (Rodríguez González y Celestino, 2017: 189, fig. 9). El análisis realizado a un conjunto de platos y cuencos procedentes de la 
estancia 100 nos permitió determinar que la gran mayoría de ellos han sido fabricados en el yacimiento, con arcillas procedentes del entorno (Celestino et al. 2018: 243); sin embargo, del conjunto recuperado de la UE 511 debemos llamar la atención sobre una veintena de cuencos decorados a bandas rojas, tanto al interior como al exterior, de clara tradición turdetana (fig. 10a TU/16/511/15). Este conjunto destaca tanto por su homogeneidad decorativa como por la presencia, en varios ejemplares, de dos perforaciones en su perfil, justo debajo del labio, para facilitar su suspensión.

Así mismo, del conjunto de platos recuperados entre la vajilla de mesa debemos destacar tres ejemplares, de perfil carenado, cuyos diámetros oscilan entre los 22 y $24 \mathrm{~cm}$ (fig. 10b). Decorados a bandas rojas, los tres presentan un perfil que nos permite incluirlos dentro de los denominados "plato de pescado", el tipo II.B. de Escacena (1987: 235), aunque solo dos de ellos presentan pocillo central. Las producciones localizadas en el valle del Guadalquivir han sido identificadas como imitaciones de platos áticos, presentes ya en el s. V a.C. en la zona gaditana (García Fernández, 2914:214); sin embargo, la forma presente en los ejemplares del Turuñuelo bien podrían entenderse como una evolución procedente de un alfar local en el que se intenta imitar la producción de platos

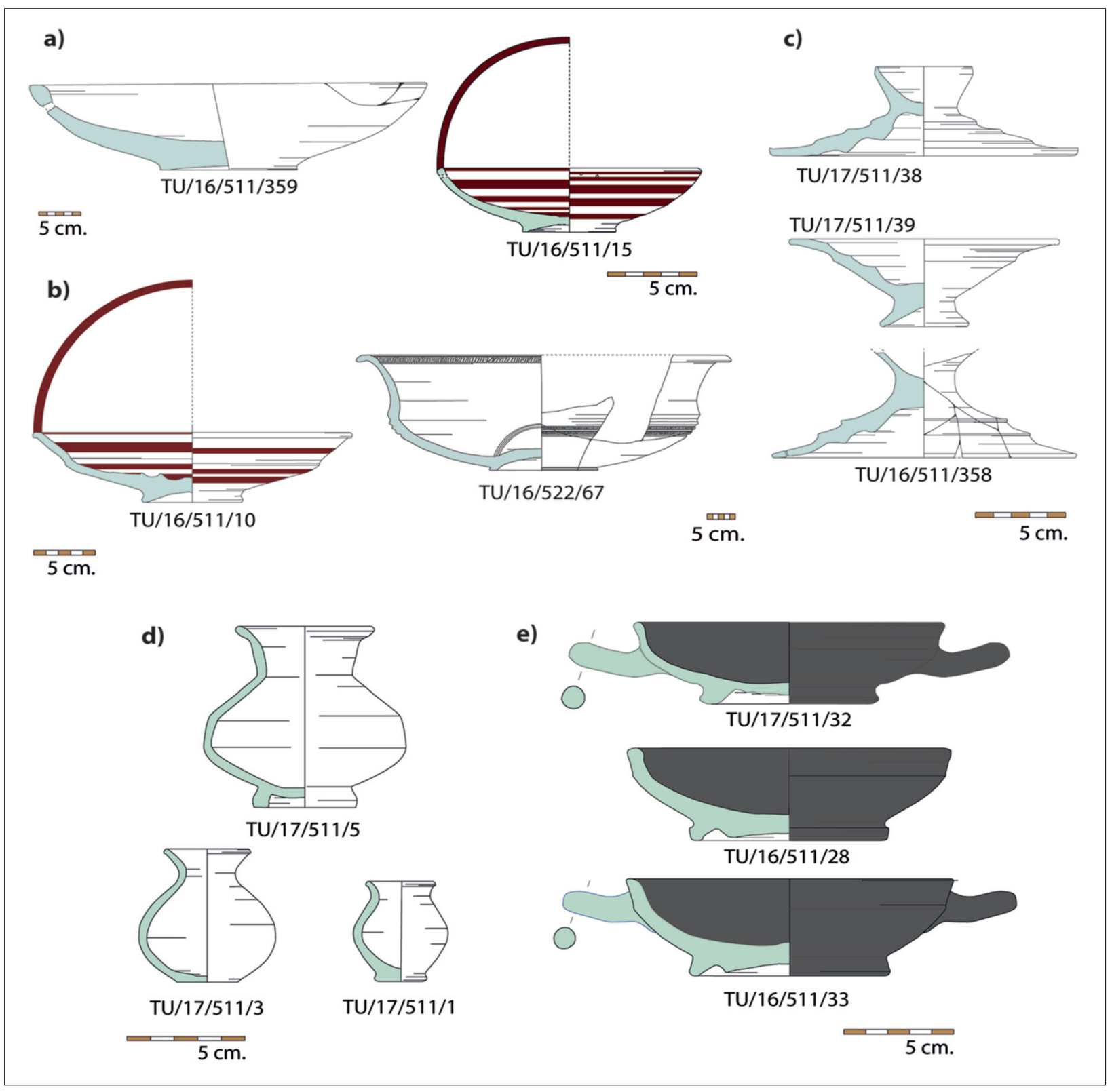

Figura 10. Selección de vajilla de mesa procedente de la estancia S-1 del yacimiento de Casas del Turuñuelo. (Dibujo: Sabah Walid. CConstruyendo Tarteso). 
fenicios de los s. VII - VI a.C. presentes en las costas andaluzas.

Por su parte, la influencia de la tradición alfarera fenicia aparece representada en la vajilla de mesa del Turuñuelo por cuatro ejemplares completos que imitan formas propias de las cerámicas de engobe rojo. Se trata de recipientes de perfil escalonado, tanto al interior como al exterior, con un borde completamente plano y muy pronunciado y un pie troncocónico muy desarrollado que presentan un rehundimiento central (fig. 10c). Los paralelos más cercanos a este tipo de piezas se localizan en la necrópolis de Medellín y se corresponden con la forma $2 \mathrm{~B}$ de las producciones de barniz rojo, concretamente con las procedentes del taller C3, con las que las piezas del Turuñuelo guardan más relación por la tonalidad de sus pastas y por la presencia de agujeros basculares practicados antes de la cocción de la pieza (AlmagroGorbea, et al., 2008: 602, 612). Los ejemplares de Medellín han sido interpretados como un posible "frutero" o copa. Aunque esta primera identificación podría ser considerada, no creemos que su interpretación como copa sea correcta. Su borde plano y alargado hace imposible que este recipiente sea empleado para beber, un hecho al que se suma su escasa capacidad por la poca profundidad que presentan.

Frente a esta lectura, proponemos para estas piezas una función como tapaderas para cubrir un plato o un cuenco, siguiendo la misma idea que las tapaderas empleadas para cubrir los lekánes o las tapas de las "urnas de orejetas perforadas" típicas de la alfarería ibérica, con las que las tapaderas de perfil escalonado del Turuñuelo guardan cierta similitud técnica y morfológica, principalmente por la presencia de un pomo en forma de botón, el agarre, confundido en diversas ocasiones con el pie de una copa.

El análisis de la distribución de los hallazgos correspondientes a las tapaderas de lekáne muestra una dispersión concentrada en el levante mediterráneo y una cronología que arranca en el s. VI a.C. (Sala, 1998: 192).Así, contamos con ejemplares en yacimientos tan destacados del Mediterráneo peninsular como la necrópolis de El Puntal (Sala y Hernández, 1998: 230, fig. 11,11), La Albufereta (Verdú, 2009: 99), El Oral (Sala, 1998: 187) o Puig d'Alcoi (Grau, 2000-2001, fig. 43; 2002, fig. 7-6).

Mientras, la dispersión de las tapaderas de urnas de orejetas perforadas es mucho más heterogénea, pues, aunque el mayor volumen también se concentra en el levante peninsular (López Bravo, 2002: 100, fig. 1) y la Alta Andalucía (correspon- diente al Grupo 14 de la tipología de Pereira (1988: 166, fig. 14), contamos con ejemplos en yacimientos del interior peninsular como Castellones del Ceal (Jaén) (Pereira, 1988: 151, fig. 5, 10) o el Castrejón de Capote (Badajoz) (Berrocal-Rangel, 1994: 196), aunque el número presente en este último yacimiento es muy reducido. El origen concreto de esta tipología de urnas y sus tapaderas sigue siendo desconocido, aunque todos los indicios apuntan a una procedencia centro mediterránea (Pereira y Rodero, 1983), cuyo auge peninsular se producirá en el s. VI a.C.; concretamente los ejemplares más antiguos proceden del yacimiento de Peña Negra de Crevillente (Alicante) (López Bravo, 2002: 100).

El contexto de aparición de estas piezas es funerario en la gran mayoría de los casos, incluso en el enclave extremeño donde se localizan los paralelos más cercanos a los ejemplos de Casas del Turuñuelo, la necrópolis de Medellín. Bien es cierto que las necrópolis constituyen escenarios cerrados, lo que favorece a la conservación de los objetos ocultos en las sepulturas, pero, como apuntábamos en la introducción del trabajo, el sistema de amortización de los túmulos del Guadiana favorece la correcta preservación de los restos que estos edificios atesoran. Por ello, aunque sería conveniente revisar algunos contextos domésticos relacionados con la preparación e ingesta de alimentos y el consumo de bebidas, parece que las piezas de perfil escalonado del Turuñuelo pudieron emplearse a modo de tapaderas para cubrir o preservar alimentos consumidos durante el banquete; pues debemos tener también en cuenta que la llegada de materiales e influencias de la zona del levante peninsular comienza a estar cada vez más asentada (Celestino 2013: 359), a través de la ruta de los santuarios, cuya existencia fue defendida hace décadas por el profesor Maluquer de Motes (1985: 20-ss).

Una de las posibilidades que barajamos es que fueran empleadas como tapaderas de las copas de imitación griega empleadas en las actividades de libación analizadas a continuación, pues comparten diámetros similares. Así, mientras la media diametral de las copas está entre 14 y $16 \mathrm{~cm}$, la de las tapaderas está en 14,4 y $16,8 \mathrm{~cm}$. Así mismo, ambos tipos son imitaciones de producciones mediterráneas, bien sean de la cerámica ática o del engobe rojo fenicio. A falta de los resultados obtenidos de los análisis de sus pastas, la coloración y el estudio óptico de las mismas nos permite presuponer un origen local para ambos recipientes (Celestino et al. 2018), lo que a su vez 
se traduciría en la existencia de un artesanado que está imitando formas llegadas del comercio mediterráneo y una sociedad de élite que está demandando este tipo de productos para su uso en actividades rituales.

Del lote recuperado en la UE 511 procede un conjunto de urnas de diversos tamaños y perfiles (fig. 10d) que posiblemente estén relacionadas con las dos actividades diferenciadas a partir de los elementos arquitectónicos documentados en la estancia: el banquete y la posible realización de sacrificios o rituales vinculados a la presencia de un altar en forma de piel de toro. Esta diferencia radica en los tamaños que presentan las urnas, pues al menos cuatro ejemplares pueden ser considerados miniaturas. Estos recipientes serán sometidos a análisis de contenido con el objetivo de determinar qué tipo de sustancias contenían, pues bien podría tratarse de algún tipo de esencia.

Por su parte, las urnas de mayor tamaño presentan diversos perfiles que llevan a pensar que no existe un modelo estandarizado, sino que las diversas formas responden a los gustos de los diferentes talleres que las producen (Escacena, 1987: 446). A rasgos generales, las urnas de la "estancia del banquete" presentan perfiles de tendencia ovoide o bitroncocónicos, de cuello alto y abocinado, boca ancha y labios exvasados, con un pie pronunciado. Sus pastas naranjas y rosas nos llevan a pensar que se trata de producciones realizadas en el propio yacimiento.

El último conjunto lo conforman las copas de imitación para el consumo del vino (fig. 10e). Aunque solo uno de los ejemplares apareció completo, concretamente la única pieza que solo cuenta con un asa, la restauración del material hallado en la UE 511 ha permitido sumar 18 ejemplares más al conjunto. Se trata de vasos que imitan copas áticas del tipo Cástulo cup, cuyo comercio está extendido por las tierras del interior peninsular durante todo el s. V. a.C. (Gracia 2003; Celestino et al. 2017). Se trata de copas modeladas a torno con diámetros que oscilan entre los 14 y los $16 \mathrm{~cm}$. Fabricadas con pastas depuradas de tonos marrones $\mathrm{y}$ beige, a las que se aplica un acabado alisado para darle un aspecto uniforme, la falta de equilibrio entre sus perfiles y sus asas horizontales demuestran la falta de dominio en el modelado es estas piezas.
El conjunto de copas de imitación recuperado en el yacimiento de Casas del Turuñuelo es el más numeroso de los conocidos hasta la fecha en el valle medio del Guadiana, pues en Cancho Roano, donde el volumen de cerámica ática es mucho mayor que el recuperado hasta la fecha en el Turuñuelo, solo contaban con un total de tres piezas de imitación (Gracia, 2003: 122 y 176, L. 70, 1-3). El número de piezas recuperadas es importante en tanto en cuanto nos está marcando la necesidad de producir, en el propio yacimiento, copas para repartir entre un número destacado de comensales que van a participar en el ritual de libación; siendo este tipo de objetos un elemento distintivo entre los individuos que forman parte del grupo. Una tarea pendiente es definir en qué recipientes se mezclaría el vino antes de su ingesta, pues la ausencia de cráteras nos lleva a pensar en el uso de recipientes de imitación o de otro tipo de contenedores para almacenar el vino y completar, así, las distintas fases que corresponden al simposio griego.

La abundancia de copas de imitación no sustituye la presencia de producciones áticas en el yacimiento. Sin embargo, y a falta de abordar un estudio detallado que permita determinar la existencia de una actividad ritual concreta durante el sellado del túmulo que cubre el edificio, éstas se concentran en los niveles superiores del yacimiento, concretamente en la capa de sellado con arcilla amarilla que parece cubrir toda la construcción a modo de blindaje. La presencia de este material en la cobertura del edificio nos ha llevado a pensar en la existencia de un ritual de libación final para el que los moradores del Turuñuelo se reservaron la cerámica de importación por ser considerada una vajilla de lujo.

\subsection{Los utensilios de metal}

Junto a las cerámicas, el segundo grupo de materiales que deben ser analizados es el conjunto de piezas de metal, tanto de bronce como de hierro, recuperados tanto de la unidad de relleno 511 como del suelo de la estancia, relacionados estrechamente con el ritual celebrado en este espacio. Casi todas las piezas que componen el ajuar están en proceso de restauración ${ }^{5}$, debido al mal estado de conservación de presentan por los altos niveles de humedad registrados en el yacimiento, principalmente las que corresponden a las herramientas de

5 Los trabajos de restauración de todas las piezas metálicas recuperadas en el yacimiento de Casas del Turuñuelo se están llevando a cabo en el laboratorio del Servicio de Conservación, Restauración y Científicos del Patrimonio Arqueológico (SECYR) de la Universidad Autónoma de Madrid. 

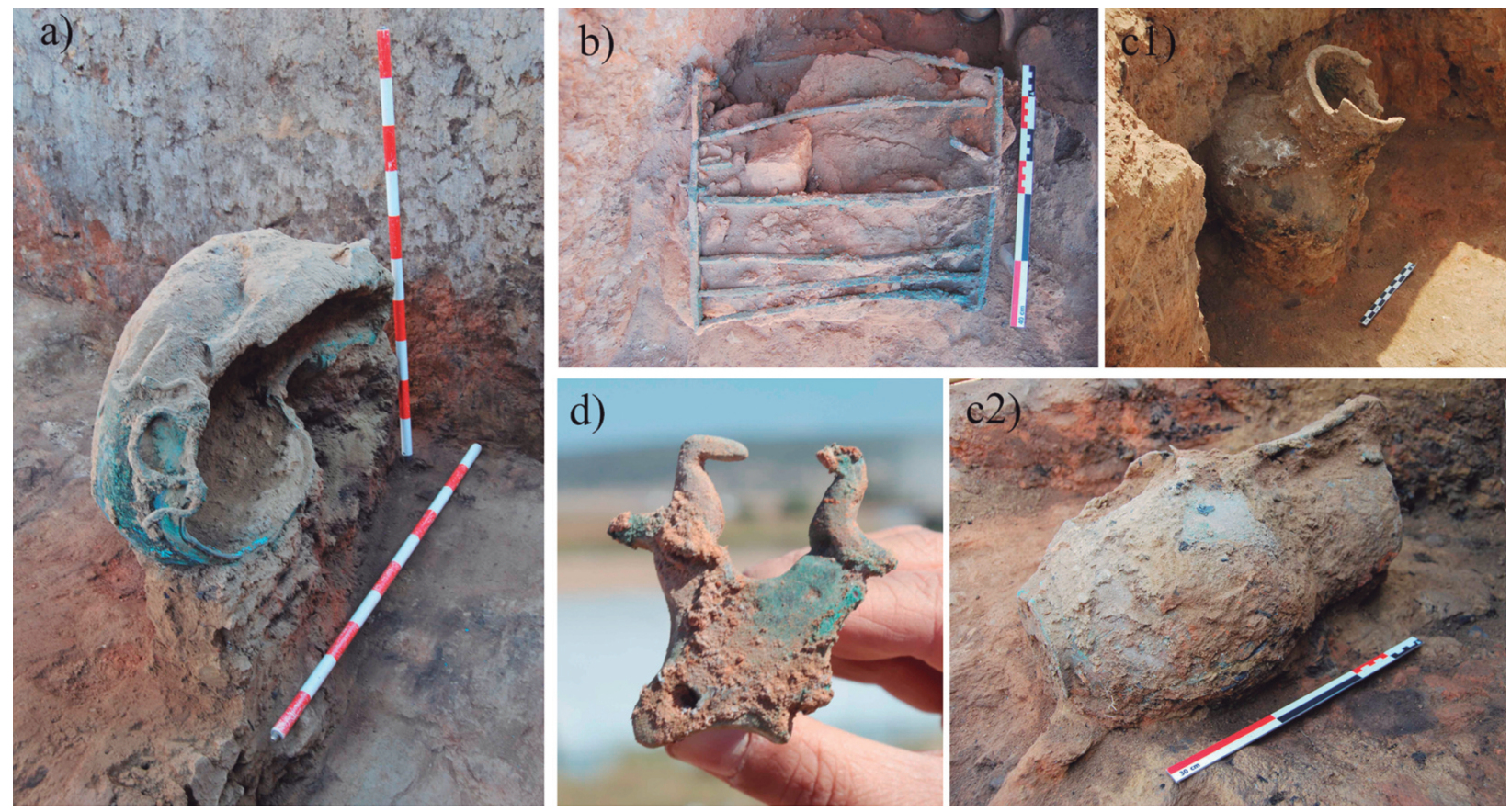

Figura 11. Conjunto de bronces procedentes de la estancia $S-1$ del yacimiento de Casas del Turuñuelo. A) Caldero. B) Parrilla. C) Jarros. D) Mango con decoración figurada. (Montaje: Carlota Lapuente. (CConstruyendo Tarteso).

labor fabricadas en hierro, como los cuchillos afalcatados, un pico o una hoz que serán objeto de estudio en un trabajo próximo; sin embargo, creemos adecuado incluir en este trabajo una breve síntesis del conjunto de piezas fabricadas en bronce, algunas de ellas ejemplos únicos en la protohistoria de la Península Ibérica.

Junto a la puerta norte de la estancia se recuperaron dos de las piezas más destacadas del conjunto: el timiaterio, analizado tras la descripción del vestíbulo, y el caldero, documentado junto a la jamba oeste de la puerta, pero ya en el interior de la estancia. Se trata de la pieza de bronce de mayores dimensiones de las documentadas hasta la fecha en el yacimiento, pues a falta de su vaciado y dibujo, podemos adelantar que posee, aproximadamente, un metro de diámetro. Sus dimensiones están complicando las labores de restauración de la pieza, cuyo interior no ha sido aún excavado, por lo que desconocemos si aun guarda restos de cualquier tipo (fig. 11a). Fabricado mediante bronce batido, se trata de un recipiente de gran tamaño con un perfil de casquete esférico. Su borde, de aparente sección triangular, cuenta con un refuerzo rectangular, una cinta que se adhiere a la pieza mediante el uso de remaches también fabricados en bronce. Cuenta con dos asas en forma de omega cuyos extremos recuerdan a dos capullos de loto cerrados, unidas al cuerpo del caldero por dos bisagras circulares.
Hasta la fecha, constituye el único ejemplo de caldero documentado completo en el ámbito tartésico. Su paralelo más cercano se localiza en el vecino yacimiento de Cancho Roano, donde se documentaron varios fragmentos de calderos de los que solo el ejemplar de la estancia $\mathrm{H}-8$ conserva buena parte de su perfil (Celestino y Zulueta, 2003: 33-34, fig. 8). Dado el contexto en el que se localiza y los materiales que le acompañan podemos otorgar a esta pieza un origen mediterráneo, si bien, de factura mucho más modesta que los conocidos en el área del Egeo y Próximo Oriente como calderos de prótomo (Jiménez Ávila, 2002). Sin embargo, la fachada atlántica de la Península Ibérica no es ajena a este tipo de materiales, pues desde el Bronce Final se atestiguan los denominados "calderos de remache" peninsulares, a los que también se otorga, no sin discusión, un origen mediterráneo (Armada, 2008; Armada y Vilaça, 2016). Aunque no se conserva un número destacado de estos calderos que permitan hacer un estudio comparativo y evolutivo completo, pues casi todos los restos recuperados corresponden a fragmentos aislados, el caldero de El Turuñuelo tiene sus paralelos más cercanos en los de Lois (Crémenes, León) y Cabárceno (Penagos, Santander) (Blas Cortina, 2007; Gerloff, 2010: 200-204, pl. 110-114), con los que guarda una estrecha relación tipológica, aunque no técnica, pues la característica de los calderos del Bronce 
Final Atlántico es que están fabricados a partir de la unión de chapas mediante remaches alineados, mientras que el caldero del yacimiento extremeño parece haber sido fabricado a partir de una sola lámina de bronce batido. No obstante, de lo que no cabe alguna duda, es que la tradición del uso de este tipo de recipientes perdura en el tiempo y arraiga en la I Edad del Hierro peninsular, vinculada igualmente a la celebración de banquetes y el consumo de carne (Armada y Vilaça, 2016: 144).

Otro de los objetos de bronce presentes en el banquete y que, al igual que el caldero, constituye una pieza única en la protohistoria del suroeste, es la parrilla (fig. 11b). De forma rectangular (44 x 38 x $18 \mathrm{~cm}$ ) está fabricada a partir de dos placas de sección rectangular ubicadas en el lado de menor longitud donde van insertas las 7 varillas de sección cuadrangular que conforma la superficie de cocinado. Ambas placas poseen una terminación en forma de ' $L$ ' en cada uno de sus extremos que hacen las funciones de patas, de tal modo que al colocar la parrilla sobre las brasas la carne no entre en contacto directo con el fuego. Por último, una de las placas de los extremos lleva inserta dos anillas en el centro posiblemente diseñadas para poder colgar la parrilla mientras no estuviese en uso.

Existen numerosos yacimientos de la protohistoria peninsular en los que han sido documentados este tipo de piezas. La mayor concentración se localiza en la Meseta, siempre vinculados a contextos funerarios, caso de los ejemplos recuperados en las necrópolis de La Mesa de Miranda (Chamartín, Ávila) (Álvarez-Sanchís, 2008) o La Osera (Chamartín, Ávila) (Álvarez-Sanchís, 2009: 207). Sin embargo, el ejemplar localizado en el yacimiento de Casas del Turuñuelo posee una característica que lo diferencia del resto de ejemplos conocidos hasta la fecha, el estar elaborado en bronce, por lo que se le supone mayor antigüedad. El resto de parrillas conocidas fueron forjadas y corresponden a unas cronologías que abarcan desde el s. IV al II a.C. (una visión reciente en Faro Carballa, 2015).

El ejemplo más próximo a nuestro caso de estudio lo constituye el fragmento de parrilla recuperado durante las excavaciones del Castrejón de Capote (Higuera la Real, Badajoz) (BerrocalRangel, 1994: 236, fig. 80), no solo porque ambos utensilios guarden similitudes tipológicas, sino porque han sido documentados en un contexto ritual, asociados a restos del consumo de animales y junto a otros elementos vinculados con la celebración de un banquete. A un entorno doméstico pertenecen también las parrillas documentadas en el ámbito ibérico, concretamente en cronologías que abarcan los s.IV - III a.C. (Faro Carballa, 2015: 80). A través del estudio cerámico ya hemos establecido algunas conexiones con el área del levante peninsular, por lo que no sería extraño que este tipo de objetos e ideas estén llegando a través de esta misma ruta comercial.

El servicio del vino se completa con el hallazgo de dos jarros de bronce (fig. 11c), aunque la presencia de varios fragmentos informes y alguna fracción de borde nos invita a pensar en la posible existencia de un tercer ejemplar. Ninguno de los jarros fue recuperado sobre el suelo de la estancia, pues uno se localizó a la altura del altillo o ventana del muro este de la habitación, mientras que el segundo se halló en el relleno 511, justo al lado contrario del depósito de cerámicas. Ambos ejemplares presentan un cuerpo ovoide con el cuello cilíndrico y el borde recto, sin desarrollar; sin embargo, presentan una diferencia en sus bases que puede marcar la variación cronológica de ambos recipientes. Así, mientras el ejemplar documentado en el relleno de la estancia junto al altillo presenta una base desarrollada cónica, similar a los ejemplares de Espartinas (Sevilla) y Cancho Roano (Forma B-III de Celestino, 1991); el ejemplar de la UE 511 posee una base plana, lo que permite incluirlo dentro del Grupo B de Jiménez (2002: 52), cuyo paralelo más cercano se localiza en Villanueva de la Vera, si bien, el ejemplar del Turuñuelo cuenta con una decoración mucho más austera, pues su asa, de sección rectangular, únicamente cuenta con una decoración incisa acanalada que recorre la superficie de la misma desde el borde al arranque del cuello cilíndrico. La cronología de este último ejemplar se sitúa en la última centuria del s. VII a.C. (Jiménez Ávila, 2002: 65), mientras que los jarros con pie cónico se fechan a partir del s. VI a.C. (Celestino, 1991: 80). Por último, el alto grado de oxidación que presentan ambos recipientes no ha permitido determinar todavía si el arranque del asa a la altura del cuello cuenta con una típica decoración de palmeta, algo que solo desvelará la actual restauración de las piezas.

En relación directa con los jarros y el servicio del vino se encuentra una de las piezas más destacadas del conjunto por tratarse del primer ejemplar recuperado completo. Se trata de un colador de bronce, fabricado a partir de un disco cóncavo de $12,7 \mathrm{~cm}$ de diámetro y un alambre retorcido que hace las funciones de asa. La parte central del disco está perforada con pequeños agujeros destinados a escanciar el vino e impedir el paso de posos o 
desperdicios. En este sentido, sus dimensiones permiten relacionarlo con los dos jarros de bronce localizados en la misma estancia en cuya boca encaja a la perfección, por lo que no cabe duda de que era empleado para colar el vino que, posteriormente, desde los jarros se serviría en las copas. Hasta la fecha, el único paralelo conocido es el fragmento de colador documentado en la estancia H-9 de Cancho Roano (Celestino y Zulueta, 2003: 5758, fig. 17.4).

El conjunto de piezas de bronce lo completan cuatro platos de balanza en proceso de restauración, un cascabel, varios fragmentos informes, un juego de 9 anzuelos y el extremo final de un mango decorado con una forma de piel de toro y dos palomas, sin duda la pieza más singular del repertorio por el simbolismo que desprende. Se trata de un vástago alargado $(14,5 \mathrm{~cm})$ de sección cuadrada, fabricado mediante la técnica de fundido. En uno de sus extremos conserva una decoración figurativa en la que se representa una piel de toro con sus esquinas inferiores perforadas sobre la que descansan dos palomas enfrentadas (fig. 11d). La curvatura que presenta el vástago y la disposición de la escena nos ha llevado a interpretar la pieza como el posible extremo de un báculo, de tal forma que al asir el vástago la decoración quedaría expuesta sobre el puño de quien la portara.

A falta de conocer la funcionalidad exacta de la misma, la importancia de este objeto radica en el simbolismo de su iconografía. La forma de piel de toro se ha relacionado en reiteradas ocasiones con el dios Baal (Celestino, 2008; Escacena y Coto, 2010; Gómez Peña, 2017), una representación recurrente en la toréutica tartésica, como así puede observarse en ejemplos como la piel de toro dibujada como manta sobre el lomo del caballo de Cancho Roano (Celestino y Zulueta, 2003: 52-ss, fig. 16), la forma adoptada por las bandejas de El Gandul y La Joya o la reciente interpretación del timiaterio de la tumba 17 de La Joya (Gómez Peña, 2018).

Mucho más abundantes son las representaciones de aves, tanto en la cerámica como la toréutica de la I Edad del Hierro del Suroeste peninsular (una visión reciente en Arruda, 2016). A pesar del esquematismo que presentan los ejemplares documentados en la pieza del Turuñuelo, no parece que haya dudas sobre su identificación con dos palomas y su interpretación como representantes de la divinidad Ishtar/Astarté, un mecanismo atestiguado en diversos puntos del Mediterráneo (Arruda, 2016: 419). Dos palomas enfrentadas aparecen representadas en el bocado de caballo de Cancho Roano (Blech, 2003: 162, fig. 2), así como en el quemaper- fumes de la Quéjola, Albacete (Blánquez y Olmos, 1993), constituyendo estos ejemplos nuestros paralelos más cercanos.

\section{SACRIficios a loS Dioses}

El análisis arquitectónico y material de los restos documentados en la estancia del banquete ha permitido diferenciar dos fases del ritual de comensalidad: por un lado, la preparación de los alimentos y, por otro lado, su consumo. En el tránsito entre ambas actividades se inserta el acto de inmolación o dedicación a la divinidad de los alimentos que van a ser degustados, un acto que puede comprender el sacrificio de animales que posteriormente va a consumirse o acciones complementarias no cruentas como la realización de libaciones. Para identificar estos espacios de inmolación se han reconocido una serie de elementos que participan de la actividad litúrgica, desde la presencia de altares o mesas de ofrenda, a la existencia de diversos objetos que reflejan la celebración del rito (Cabrera Díez, 2010: 124-ss).

Todos estos elementos parecen estar presentes en la estancia objeto de estudio. El altar en forma de piel de toro acompañado de una mesa de servicio y, al menos, una mesa de ofrendas, a lo que se suma la existencia de abundantes restos óseos cuyo estudio será determinante para definir la práctica sacrificial celebrada en este espacio. A estas estructuras se suman los restos cerámicos y metálicos relacionados con la realización de libaciones y el consumo del vino, otra fase concebida dentro de las etapas del banquete. Sin embargo, debemos sumar a este elenco una última pieza que certifica la identificación de este ámbito con un espacio relacionado con la ritualidad. Se trata de una cuarcita de tonalidad marrón y forma cilíndrica $(0,25 \times 0,5 \mathrm{~m})$ recuperada en la unidad de relleno 511, que en una primera lectura del conjunto fue identificada como un posible alisador. El análisis macroscópico de la pieza nos permitió constatar que los extremos de la misma habían sido trabajados mediante abrasión con el objetivo de darles un aspecto redondeado, pero además se constató que la pieza había sido pintada de rojo (fig. 12). Esta identificación nos llevó a redefinir la funcionalidad del objeto e identificarlo con un betilo, la representación anicónica de la divinidad (Seco Serra, 2010: 135-137).

El betilo recuperado en el Turuñuelo no es un ejemplo único pues contamos con dos paralelos en el área de Tarteso que representan el mismo tipo (Toscano Pérez, 2019). La primera pieza procede de la tumba 18 de la Joya y pertenece a un objeto cilín- 


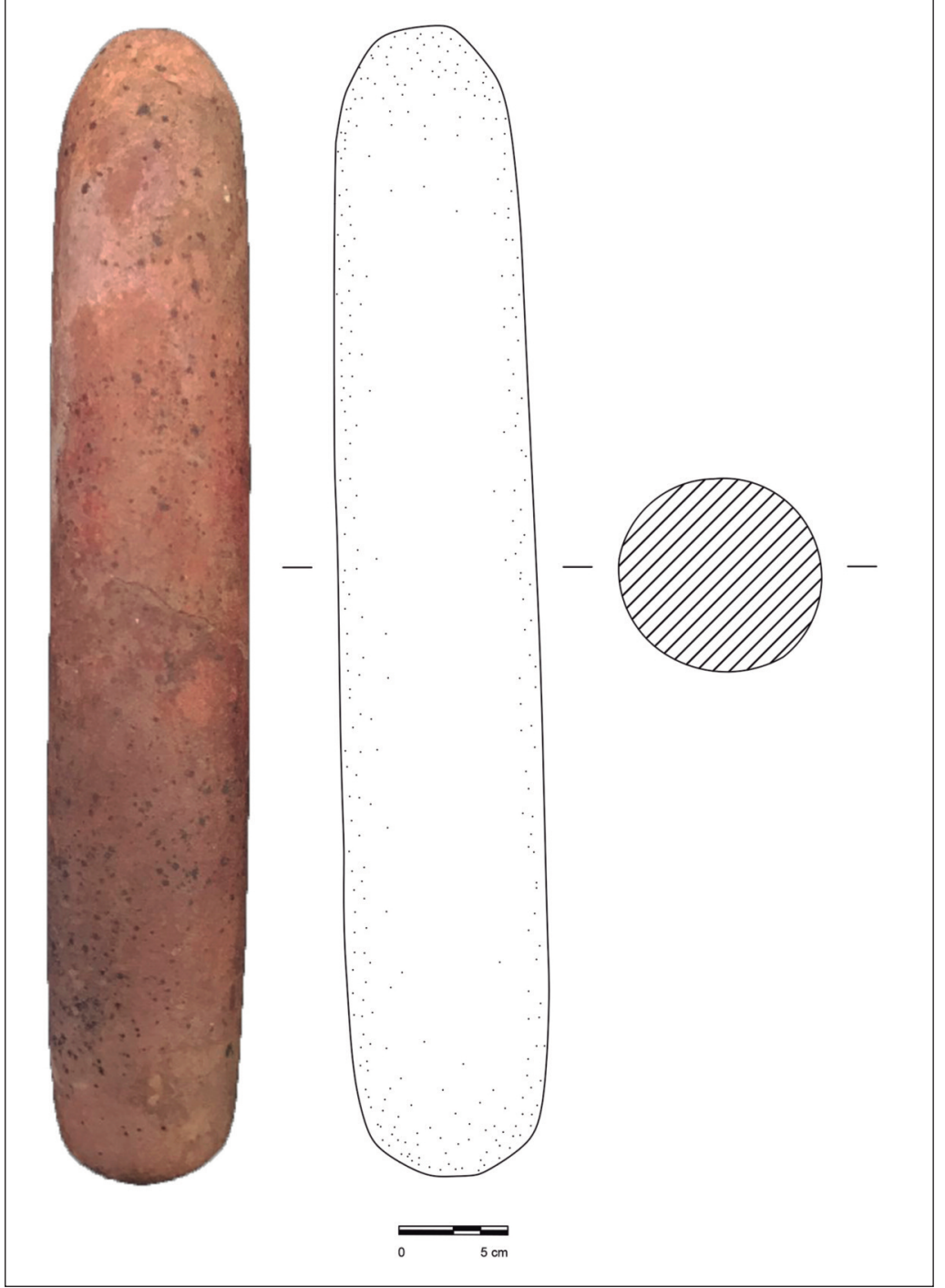

Figura 12. Betilo cilíndrico documentado en la UE 511 de la estancia S-1 del yacimiento de Casas del Turuñuelo. (Montaje: Carlota Lapuente. (C) Construyendo Tarteso).

drico de arenisca también trabajado en sus extremos (Garrido y Orta, 1978: 143). El segundo ejemplo procede de un reciente hallazgo realizado en el poblado de Tejada la Vieja durante las actividades de limpieza y consolidación realizadas en el yacimiento durante el año 2015. A diferencia del ejemplar del Turuñuelo, el betilo de Tejada cuenta con unas dimensiones mayores y uno de sus extremos ha sido decorado mediante la ejecución de cinco perforaciones a partir de un elemento metálico.

La diferencia fundamental que presentan las tres piezas es el contexto en el que han sido documentados. Mientras el betilo de la Joya procede de un ambiente funerario, la pieza de Tejada fue recuperada dentro de un área de viviendas, lo que no encaja dentro del contexto cultual al que responde el yacimiento de Casas del Turuñuelo. Sin embargo, el ejemplar de la "estancia del banquete" no es un caso aislado dentro del suroeste peninsular, pues existen claros ejemplos en yacimientos claves del ámbito tartésico (una revisión reciente en Celestino y Rodríguez González), donde conviven la presencia de altares y signos de la celebración de actividades litúrgicas junto a la existencia de betilos, caso de El Carambolo (Sevilla) (Fernández Flores et al., e.p.) y el Castro dos Ratinhos (Moura, Portugal) (Berrocal-Rangel y Silva, 2010); sin embargo, el ejemplo que más se acerca a nuestro caso de estudio es nuevamente el santuario de Cancho Roano (Zalamea de la Serena, Badajoz), de cuyo foso fueron recuperados dos betilos que han sido puestos en relación con las estructuras documentadas en las diferentes fases de la estancia $\mathrm{H}-7$ o sancta santorum (Celestino, 2001: 56).

\section{A MOdO DE CONCLUSIÓN}

El análisis estratigráfico, constructivo y material de la denominada "estancia del banquete" o S-1 permite concluir que este espacio estuvo destinado, desde su construcción, al preparado y consumo de alimentos; sin embargo, en el momento previo al incendio y clausura del edificio, la habitación fue testigo de la celebración de un banquete cuyo objetivo era conectar el final de la vida del edificio con el beneplácito de la divinidad a la que fueron consagradas las diferentes liturgias celebradas en el mismo. De ese modo, el análisis tipológico de los materiales depositados sobre el pavimento de la estancia muestra la existencia de una escena vinculada con la preparación de los alimentos, como asílo refleja el abundante elenco de cerámica de cocina recuperado, los cuchillos afalcatados y el molino barquiforme documentado en la esquina suroeste de la habitación, entre otros materiales. Este estudio material encaja a la perfección con la lectura microestratigráfica realizada de este ámbito a partir del perfil correspondiente al vano oeste localizado en la estancia, donde la superposición de pavimentos y restos de carbones y cenizas permiten definir el uso continuo de este espacio como área para la preparación de los alimentos. 
Sin embargo, el evento celebrado antes de la clausura del edificio no se corresponde con una actividad cotidiana, sino que representa un acontecimiento excepcional como así lo refleja tanto la ejecución de una fosa donde fueron vertidos los desperdicios del banquete, como la vajilla cerámica y los objetos metálicos recuperados del relleno que cubre el nivel de uso de la habitación. Curiosamente, los materiales recuperados de este relleno fueron depositados en un mismo punto, lo que muestra la intencionalidad implícita en la actividad, al tiempo que abre la puerta a la posibilidad de que el consumo de bebida y comida no se realizase en este espacio, sino en un ámbito contiguo aun por excavar. A este respecto, todos los indicios parecen apuntar a que la actividad del banquete se desarrolló en la estancia oeste, paralela a la habitación 100 con la que posiblemente comparta unas dimensiones similares. Eso explicaría la anchura del vano de su puerta, la presencia de una posible estera o alfombra que cubre el pavimento de acceso y que la ventana o altillo se localice justo frente a la misma, propiciando su iluminación directa.

Pero existe otra razón para considerar que este espacio estuvo solo destinado a la preparación y ofrenda de alimentos y bebidas. No es otra que sus reducidas dimensiones, a las que se suma la presencia de varias estructuras sobre el suelo que complican la convivencia de un destacado número de personas en el mismo, un mínimo de dieciocho integrantes si tenemos en cuenta que este es el número de copas de imitación para beber vino recuperadas de la UE 511.

Esta primera lectura de la estancia del banquete abre la puerta a un buen número de preguntas que solo la continuidad de las excavaciones podrá contestar. Quizás las dos más importantes giren en torno a la razón por la cual se llevó a cabo el banquete y el motivo que llevó a los moradores de El Turuñuelo a abandonar este enclave, así como a definir la figura de su anfitrión, un personaje con capacidad política y económica para liderar el ritual que gira en torno a la clausura del edificio de Casas del Turuñuelo, en cuya liturgia podemos ya diferenciar la celebración de un banquete y la realización de una gran hecatombe que convierten al yacimiento en un ejemplo único de la protohistoria peninsular.

El siguiente paso a seguir es abordar el análisis de esta estancia a partir del modelo teórico definido por la todavía joven Arqueología del Banquete (Van del Veen, 2003; Sardà y Dioli, 2009), cuyo objetivo es el análisis de comportamientos sociales a partir de la huella material que la celebración de un banquete deja en el registro arqueológico. Es posible que este análisis, que podremos llevar a cabo cuando conozcamos la estancia contigua, nos permita conocer mejor la funcionalidad que ejerció el edificio de Casas del Turuñuelo dentro del poblamiento del valle medio del Guadiana.

\section{Bibliografía}

Almagro-Gorbea, M.; Mederos, A. y Torres, M. (2008): "Cerámica de Barniz Rojo", en M. AlmagroGorbea (dir.), La necrópolis de Medellín II. Estudio de los hallazgos. Madrid: 593-622.

Álvarez-Sanchís, J. R. (ed.) (2008): Vettones. Pastores y guerreros en la Edad del Hierro. Catálogo de la exposición. Museo Arqueológico Regional de Madrid. Madrid.

Álvarez-Sanchís, J. R. (2009): "Huellas del consumo del vino en las necrópolis vettonas", en C. Sanz y F. Romeno (eds.), El vino y el banquete en la Europa prerromana. Valladolid: 193-211.

Armada, X-L. (2008): “¿Carne, drogas o alcohol? Calderos y banquetes en el Bronce Final de la Península Ibérica". Cuadernos de Prehistoria y Arqueología de la Universidad de Granada 18: 125-162.

Armada, X-L. y Vilaça, R. (2016): "Rituales de comensalidad en el Bronce Final de la Iberia atlántica: artefactos metálicos, contextos e interpretación", en R. Vilaça y M. Serra (eds.), Matar a fome, alimentar a alma, criar sociabilidades. Alimentaçao e comensalidade nas sociedades pré e proto-históricas. Coimbra: 127-157.

Arruda, A. M. (2016): "'À vol d’oiseau. Pássaros, passarinhos e passarocos na Idade do Ferro do sul de Portugal", en A. Catarina, A. Carvalho y C. Viegas (eds.), Terra e Água. Escolher sementes, invocar a Deusa. Estudos em homenagem a Victor S. Gonçalves. Estudos \& Memórias, 9. Lisboa: 403-423.

Bandera, Ma . L. de la y Ferrer Albelda, E. (1994): "El timiaterio orientalizante de Villagarcía de la Torre (Badajoz)". Archivo Español de Arqueología 67: 41-61, https://doi.org/10.3989/aespa.1994.v67.397.

Berrocal-Rangel, L. (1994): El altar prerromano de Capote. Ensayo etno-arqueológico de un ritual céltico en el suroeste peninsular. Universidad Autónoma de Madrid. Madrid.

Berrocal-Rangel, L., Celestino, S. y Rodríguez González, E. (e.p.): "Textiles and Rituality in the Late Tartessian Culture of the Guadiana Valley". Saguntum Extra.

Berrocal-Rangel, L. y Silva, A. C. (2010): O Castro dos Rathinos (Barraguem do Alqueva, Moura). Escavaçoes num povoado proto-histórico do Guadiana, 2004-2007. O Arqueólogo Português 6. Lisboa. 
Blánquez, J. y Olmos, R. (1993): “El poblamiento ibérico antiguo en la provincia de Albacete. El timiaterio de La Quéjola (San Pedro) y su contexto arqueológico", en J. Blánquez, R. Sanz y Mª T. Musat (coords.), Arqueología en Albacete. Fornadas de arqueología albacetense en La Universidad Autónoma de Madrid. Patrimonio Histórico. Arqueología 6, Toledo: 85-108.

Blas Cortina, M. A. (2007): "Los calderos de Lois (León) y Cabárceno (Cantabria) y su paradero subterráneo: ¿azar y oblación a la tierra?, en J. Celis, G. Delibes, J. Fernández Manzano y L. Grau (eds.), El hallazgo leonés de Valdevimbre y los depósitos del Bronce Final Atlántico en la Península Ibérica. León: 238-256.

Blech, M. (2003): "Elementos de atalaje de Cancho Roano", en S. Celestino (ed.), Cancho Roano IX. Los materiales arqueológicos II. Mérida: 157-192.

Cabrera Díez, A. (2010): El ritual de sacrificio de animales en la cultura ibérica: una perspectiva arqueológica. Tesis doctoral inédita. Universidad Complutense de Madrid.

Celestino Pérez, S. (1991): "Nuevos jarros tartésicos de bronce en el sur peninsular". Madrider Mitteilungen 32: 52-85.

Celestino Pérez, S. (2001): Cancho Roano. Madrid.

Celestino Pérez, S. (2001b): "Los santuarios de Cancho Roano. Del indigenismo al orientalismo arquitectónico", en D. Ruiz Mata y S. Celestino (coord.), Arquitectura Oriental y Orientalizante en la Península Ibérica. Madrid: 17-56.

Celestino Pérez, S. (2008): "Los altares en forma de piel de toro de la Península Ibérica”, en J.J.Justel, J. P. Vita y J. Á. Zamora (eds.), Las culturas del Próximo Oriente Antiguo y su expansión mediterránea. Zaragoza: 321-348.

Celestino, S. (2013): "La aportación de J. Maluquer de Motes al estudio de Tarteso". Revista d'Arqueologia de Ponent 23: 353-363.

Celestino, S. (2016): Tarteso. Territorio y cultura. Ariel. Barcelona.

Celestino, S. y López Ruiz, C. (2016): Tartessos and the phoenicians in Iberia. Oxford University Press. Oxford.

Celestino, S. y Rodríguez González, E. (2019a): "Un espacio para el sacrificio: el patio del yacimiento tartésico de Casas del Turuñuelo". Complutum 30 (2).

Celestino, S. y Rodríguez González, E. (2019b): “El santuario de Cancho Roano C: un espacio consagrado a Baal y Astarté”. Ophiussa 3: 27-44.
Celestino, S., Gracia, F. y Rodríguez González, E. (2017): "Copas para un banquete. La distribución de cerámicas áticas en Extremadura”, en X. Aquilué, P. Cabrera y M. Orfila (coord.), Homenaje a Glòria Trias Rubiés: cerámicas griegas de la Península Ibérica: cincuenta años después (1967-2017). Barcelona: 140-149.

Celestino Pérez, S., Rodríguez González, E., Bashore, G., Dorado, A. y Lapuente, C. (2018): "La arquitectura como actividad productiva: tres casos de estudio de época tartésica en el valle medio del Guadiana", en A. Navarro y E. Ferrer (coords.), Trabajo Sagrado. Producción y Representación en el Mediterráneo Occidental durante el I Milenio a.C. Spal Monografias XXV, Sevilla: 231-248.

Celestino Pérez, S. y Zulueta de, P. (2003): "Los bronces de Cancho Roano", en S. Celestino (ed.), Cancho Roano IX. Los materiales arqueológicos II. Mérida: 11 123.

Díes Cusí, E. (1994): La arquitectura fenicia de la península ibérica y su influencia en las culturas indígenas. Tesis doctoral inédita. Valencia.

Escacena, J. L. (1987): Cerámicas a torno pintadas andaluzas de la II Edad del Hierro. Tesis doctoral microfilmada. Cádiz.

Escacena, J. L. y Coto, M. (2010): “Altares para la eternidad”. Spal 19: 149-185, https://doi.org/10. 12795/spal.2010.i19.07.

Escacena, J. L. e Izquierdo, R. (2000): “Altares para Baal". Arys 3: 11-40.

Faro Carballa,J. A. (2015): "La necrópolis de El Castillo (Castejón, Navarra). Vajilla e instrumental metálico de sacrificio y banquete en el valle medio del Ebro (s. VI-III a.C.)". Lvcentom XXXIV: 31-118, https://doi.org/10.14198/LVGENTVM2015.3 4.03 .

Fernández Flores, A., Casado Ariza, M. y Prados Pérez, E. (e.p.): "Primeros vestigios de la colonización fenicia en el Carambolo. El edificio inicial (Carambolo V), función y cronología" J.L. López Castro (ed.): Entre Útica y Gadir. Granada: 213-239.

Ferrer, E. y García Fernández, F. J. (2008): “Cerámica Turdetana", en D. Bernal y A. Ribera i Lacomba (eds.), Cerámiedcas hispanorromanas. Un estado de la cuestión. Cádiz: 201-219.

García Fernández, F. J. (2007): “Etnología y etnias de la Turdetania en época romana". Cuadernos de Prehistoria y Arqueología de la Universidad Autónoma de Madrid 33: 117-143, https://doi.org/10.15366/cupauam 2007.33.006. 
García Fernández, F.J. (2014): "El peso de la tradición: imitación y adaptación de formas helenísticas en la cerámica común turdetana (s. V-I a.C.)", en F. J. García Fernández y E. García Vargas (eds.), Comer a la moda: imitaciones de la vajilla de mesa en Turdetania y la Bética Occidental durante la Antigüedad (s. VI a.C. - VI d.C.), Colecció Instrumenta 46. Barcelona: 205237.

García Fernández, F. J. y García Vargas, E. (2010): "Entre gaditanización y romanización: repertorios cerámicos, alimentación e integración cultural en turdetania (s. III-I a.C.). Saguntum Extra 9: 115-134.

García Fernández, F. J. y Sáez Romero, A. (2012): "Influencias de tradición helenística y centromediterráneas en las producciones comunes del área turdetana”, en R. Morais, A. Fernández y Mª J. Sousa (eds.), As produções cerâmicas de imitaçâo na Hispania. Actas del II Congreso Internacional de la SECAH - Ex Officina Hispana. Porto: 109-124

Garrido, J. P. y Orta, E. Ma . (1970): Excavaciones en la necrópolis de «La foya». Huelva. $1^{a}$ y $2^{a}$ Campañas, Excavaciones Arqueológicas de España 71. Madrid.

Garrido, J. P. y Orta, E. Ma . (1978): Excavaciones en la necrópolis de "La Foya». Huelva. 3", $4^{a}$ y $5^{a}$ Campaña, Excavaciones Arqueológicas de España 96. Madrid.

Gerloff, S. (2010): Atlantic Couldrons and Buckets of the Late Bronze Early Iron Ages in Western Europe with a Review of Comparable Vessels from Central Europe and Italy. Prähistorische Bronzefunde, 11 (18). Stuttgart.

Gómez Peña, A. (2017): La piel de toro como símbolo religioso y marcador identitario de la colonización fenicia de la península ibérica. Una lectura darwinista. Tesis doctoral inédita. Universidad de Sevilla.

Gómez Peña, A. (2018): "Nueva interpretación simbólica sobre el timiaterio de La Joya (Huelva)". Folia Phoenicia 2: 214-217.

Gracia, F. (2003): "Las cerámicas áticas del palaciosantuario de Cancho Roano”, en S. Celestino (ed.), Cancho Roano VIII. Los materiales arqueológicos I. Mérida: 23-193.

Grau, I. (2000-2001): La formación del mundo ibérico en los valles de L'Alcoià y El Comtat (Alicante), Anejo I de la Revista Lucentum. Alicante.

Grau, I. (2002): La organización del territorio en el área central de la Contestania Ibérica. Publicaciones Universidad de Alicante. Alicante.

Jiménez Ávila, J. (2002): La toréutica orientalizante en la Península Ibérica. Real Academia de la Historia. Madrid.
López Bravo, F. (2002): "La urna ibérica de orejetas perforadas". Complutum 13: 97-116.

Maluquer de Motes, J. (1957): "De metalurgia tartésica: el Bronce Carriazo". Zephyrus 8: 157-168.

Maluquer de Motes, J. (1985): “El comercio continental focense en la Extremadura central". Monografies Emporitanes VII: 19-26.

Marín-Aguilera, B., Rodríguez-González, E., Celestino, S. y Gleba, M. (2019): "Dressing the sacrifice: textiles, textile production and the sacrificial economy at Casas del Turuñuelo in fifth-century BC Iberia". Antiquity 93: 933-953, https://doi.org/ 10.15184/aqy.2019.42.

Martín Sánchez, A., Nuevo, Mª .J., Ojeda, M. A., Guerra Millán, S., Celestino, S. y Rodríguez González, E. (2019): "Analytical techniques applied to the study of mortars and coatings from the Tartessic archaeological site "El Turuñuelo" (Spain)". Radiation Physics and Chemistry, https:/ / doi.org/10.1016/j.radphyschem.2019.05.031.

Pereira, J. (1988): "La cerámica ibérica de la cuenca del Guadalquivir. I. Propuesta de clasificación". Trabajos de Prehistoria 45: 143-173, https://doi.org/ 10.3989/tp.1988.v45.i0.608.

Pereira, J. y Rodero, A. (1983): "Aportaciones al problema de las urnas de orejetas perforadas", en Homenaje al profesor M. Almagro Basch, III: 47-56.

Ponce de León, M. (2004): "Geología y materiales de construcción”, en A. Rodríguez Díaz (ed.), El edificio protohistórico de La Mata (Campanario, Badajoz) y su estudio territorial’. Cáceres: 315-344.

Rodríguez Díaz, A. y Ortiz Romero, P. (2004): "La Mata, un edificio organizado", en A. Rodríguez Díaz (ed.), El edificio protohistórico de "La Mata" (Campanario, Badajoz) y su estudio territorial. Cáceres: 75-312.

Rodríguez González, E. (2018): El poblamiento del valle medio del Guadiana durante la I Edad del Hierro. Bibliotheca Praehistorica Hispana XXXIV. CSIC. Madrid.

Rodríguez González, E. y Celestino, S. (2017): "Las estancias de los dioses: la habitación 100 del yacimiento de Casas del Turuñuelo (Guareña, Badajoz)". Cuadernos de Prehistoria y Arqueología de la Universidad Autónoma de Madrid43: 179-194, https:/ / doi.org/10.15366/cupauam2017.43.006.

Rodríguez González, E., Dorado Alejos, A. y Celestino, S. (e.p.): "Medio Guadiana - Beturia", en F.J. García Fernández, A. Sáez Romero y E. Ferrer 
Albelda (coords.), Las ánforas turdetanas "tipo Macareno" cuarenta años después: actualización tipológica y nuevas perspectivas. Sevilla.

Sala, F. (1998): La cultura ibérica de los siglos VI al III a.C. en las comarcas meridionales de la contestania. Una propuesta de evolución a partir de los yacimientos de El Oral, El Puntaly La Escuera. Tesis doctoral inédita. Universidad de Alicante.

Sala, F. y Hernández Alcaraz, L. (1998): "La necrópolis de El Puntal (Salinas, Alicante): aspectos funerarios ibéricos del siglo IV a.C. en el corredor del Vinalopó". Quadernos de Prehistoria y Arqueología de Castellón 19: 221-266.

Sardá, S. (2010): "El giro comensal: nuevos temas y nuevos enfoques en la protohistoria peninsular". Herakleion 3: 37-65.

Sardà, S. y Dioli, J. (2009): “Arqueología del banquet. Ritualització, semiótica dels aliments i anàlisi contextual", en J. Dioli y S. Sardà (coords.), Ideo- logia, Pràctiques rituals y banquet al nord-est de la Península Ibèrica durant la protohistoria, Citerior. Arqueologia i Ciéncies de l'antiguitat 5. Tarragona:15-56.

Seco Serra, I. (2010): Piedras con alma: el betilismo en el mundo antiguo y sus manifestaciones en la Península Ibérica. Spal Monografias, XIII. Sevilla.

Toscano Pérez, C. (2019): "Cultos betílicos en la Turdetania onobense", en Mª E. Chávez-Álvares, Mª D. Camalich y D. Martín Socas (coords.), Un periplo docente e investigador. Estudios en homenaje al profesor Antonio Tejera Gaspar. Tenerife: 511-526.

Van del Veen, M. (2003): "When is food a luxury?", World Archaeology 34-3: 405-427, https://doi.org/ 10.1080/0043824021000026422.

Verdú, E. (2009): “Copa de pie alto (Cílica/Kýllix) de figuras rojas griega (Ática)", en M. Olcina y J. J. Ramón Sánchez (eds.), Huellas Griegas de la Contestania Ibérica. Alicante: 99. 